UCRL --53232

UCRL-53232

DE82 007989

\title{
Health and Environmental Effects Document on Geothermal Energy- 1981
}

\author{
David W. Layton \\ Lynn R. Anspaugh \\ Kerry D. O'Banion
}

Manuscript date: December 4, 1981

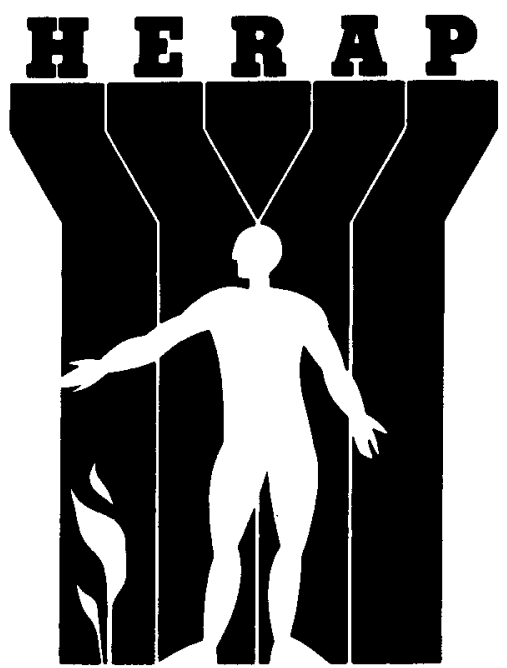

Health and Environmental

Risk Analysis Program

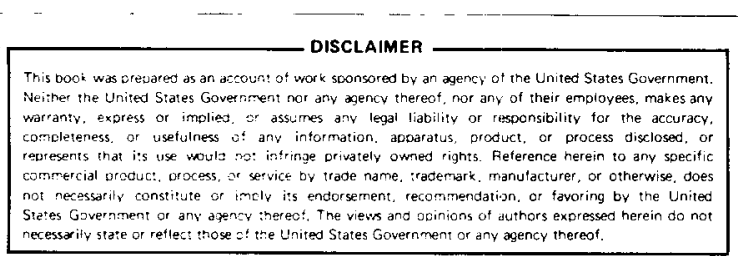

\section{Prepared for:}

Health and Environmental Risk Analysis Program Human Health and Assessment Division Office of Health and Environmental Research Office of Energy Research U.S. Department of Energy

\section{LAWRENCE LIVERMORE LABORATORY} University of California $\bullet$ Livermore, California $\bullet 94550$ 


\section{DISCLAIMER}

This report was prepared as an account of work sponsored by an agency of the United States Government. Neither the United States Government nor any agency Thereof, nor any of their employees, makes any warranty, express or implied, or assumes any legal liability or responsibility for the accuracy, completeness, or usefulness of any information, apparatus, product, or process disclosed, or represents that its use would not infringe privately owned rights. Reference herein to any specific commercial product, process, or service by trade name, trademark, manufacturer, or otherwise does not necessarily constitute or imply its endorsement, recommendation, or favoring by the United States Government or any agency thereof. The views and opinions of authors expressed herein do not necessarily state or reflect those of the United States Government or any agency thereof. 


\section{DISCLAIMER}

Portions of this document may be illegible in electronic image products. Images are produced from the best available original document. 
Executive Summary . . . . . . . . . . . . . . . . . . v Abstract . . . . . . . . . . . . . . . . . . . . . . 1 Introduction . . . . . . . . . . . . . . . . . . . 2

Overview of Potential Health and Environmental Effects . . . . . . . 3

Methodology . . . . . . . . . . . . . . . . . 4

The Reference Geothermal Power Industry . . . . . . . . . . . . 6

Geothermal Power Technologies . . . . . . . . . . . . 6

Chemistry of Noncondensing Gases . . . . . . . . . . . . . 11

Hydrogen Sulfide. . . . . . . . . . . . . . . . 11

Benzene ..................... . . 13

Mercury ........................... 15

Radon ........................ 17

Human Heal th Effects . . . . . . . . . . . . . . . . 20

Public Health. . . . . . . . . . . . . . . . . . 20

Risk Assessment Model and Uncertainty Analysis . . . . . . . 21

Effects of Hydrogen Sulfide . . . . . . . . . . . . 23

Effects of Sulfur Oxides . . . . . . . . . . . . . 25

Effects of Benzene. . . . . . . . . . . . . . . 29

Effects of Mercury...................... 32

Effects of Radon. . . . . . . . . . . . . . . 36

Arsenicalism ................... . . 38

Occupational Health. . . . . . . . . . . . . . . . 40

Ecosystem Effects . . . . . . . . . . . . . . . . . . . 43

Emissions of Hydrogen Sulfide and Carbon Dioxide. . . . . . . . . 44

Accidental Spills . . . . . . . . . . . . . . . 45

Conclusions . . . . . . . . . . . . . . . . . 48

Acknowledgments . . . . . . . . . . . . . . . . . 50

References ........................... 51 


\section{EXECUTIVE SUMMARY}

The 1981 Health and Environmental Effects Document (HEED) on geothermal energy focuses on the effects of a reference industry that produces $21,000 \mathrm{MW}$ for 30 y (i.e., $20 \times 10^{18} \mathrm{~J}$ or 20 Quads of electrical energy). That level of development is equivalent to the estimated resource potential of identified, hot-water resources in the U.S. Hot-water resources can be processed by either flashed-steam or binary-fluid geothermal power plants to produce electricity. In this HEED, however, we are primarily concerned with operation of the flashed-steam facilities because they pose greater health and environmental risks due to atmospheric emissions of noncondensing gases.

The most important noncondensing gases from a health effects standpoint are hydrogen sulfide and particulate sulfate from the atmospheric oxidation of hydrogen sulfide, benzene, mercury, and radon. We assessed the public health risks of each of these gases as well as particulate sulfate for a single, reference power plant of $100 \mathrm{MW}$; for a scenario of 3,000 $\mathrm{MW}$ of development in California's Imperial Valley; and finally, for $21,000 \mathrm{MW}$ of electricity production over $30 \mathrm{y}$ at 51 different geothermal resource areas in the western U.S. We also studied the health risk of drinking water contaminated with arsenic derived from geothermal fluids. The occupational health risks were estimated for $21,000 \mathrm{MW}$ of development to conclude the analysis of human health effects. In our ecological analysis, we examine the potential effects of hydrogen sulfide and carbon dioxide emissions on crops and forest plants and the occurrence of accidental spills of geothermal fluids that would damage soils and vegetation adjacent to power plants comprising the reference industry.

\section{PUBLIC HEALTH EFFECTS}

We summarize here the analyses performed to determine the health effects associated with exposure to hydrogen sulfide, sulfur oxides, benzene, mercury, and radon in air and arsenic in water.

Atmospheric releases of hydrogen sulfide constitute the most significant public health issue of geothermal energy production. It is a toxic gas, causing death at concentrations above 1000 parts per million by volume (ppmv) and eye damage at concentrations as low as 50 ppmv. However, the primary concern is its annoying odor, which can be detected by $20 \%$ of the population at a concentration of just 0.002 ppmv. According to our analysis, at least 29 of the 51 geothermal resource areas are likely to have one or more power plants that emit enough hydrogen sulfide to cause odor-related problems. 
- Hydrogen sulfide in the atmosphere oxidizes to particulate sulfate. We calculated the ambient concentrations of sulfate around a reference $100-\mathrm{MW}$ facility using a Gaussian dispersion model that simulates the transport, conversion, and ground deposition of hydrogen sulfide and its oxidation by-products. An individual's annual risk of premature death because of inhalation of sulfate was calculated to be $7.2 \times 10^{-8}$. If hydrogen sulfide emissions are controlled to $1 \mathrm{~g} / \mathrm{s}$ to minimize odor problems, the annual risk falls to $7 \times 10^{-9}$. Both of those estimates are based on a sulfate effects coefficient of $3.5 \times 10^{-5} \mathrm{~m}^{3} / \mathrm{\mu g} \cdot \mathrm{y}$ and a linear, no-threshold dose-response model. For $3000 \mathrm{MW}$ of power generation in the Imperial Valley, we predict 4.8 premature deaths over $30 \mathrm{y}$ without control of hydrogen sulfide emissions and 0.3 deaths with control. With $21,000 \mathrm{MW}$ of energy production over $30 \mathrm{y}$ and no hydrogen sulfide control, the mean of the probability distribution for sulfate health risk is 690 premature deaths. At the 95 th cumulative percentile for that distribution, 1900 deaths are expected. If hydrogen sulfide emissions are controlled to $36 \mathrm{~g} / \mathrm{MW}_{\mathrm{e}} \cdot \mathrm{h}$, the mean number of premature deaths becomes 9 and at the 95 th cumulative percentile, 25 deaths. Expressed in terms of $10^{18} \mathrm{~J}$ of electrical energy production, the sulfate-induced health risk is 0 to 95 premature deaths per $10^{18} \mathrm{~J}$. We have placed the lower bound at zero to reflect the possibility that there is an effects threshold above the ambient exposures we have calculated.

- Benzene has been identified as a leukemogen, and it is also found in some geothermal fluids, particularly those that are extracted from geothermal reservoirs composed of sedimentary or metamorphic rocks. The lifetime risks of incurring leukemia from exposure to benzene released from the reference $100-\mathrm{MW}$ flashed-steam facility are $2 \times 10^{-8}$ at $10 \mathrm{~km}$ from the facility and $7 \times 10^{-9}$ at $80 \mathrm{~km}$. For the scenario of $3000 \mathrm{MW}$ of development in the Imperial Valley we calculate a population risk of 0.01 excess deaths over $30 \mathrm{y}$. The mean population risk of the reference industry is 0.6 excess deaths $\left(3 \times 10^{-2}\right.$ per $\left.10^{18} \mathrm{~J}\right)$; at the 95 th cumulative percentile of risk, 1.7 deaths $\left(8.5 \times 10^{-2}\right.$ per $\left.10^{18} \mathrm{~J}\right)$ are predicted.

Mercury is frequently found in geothermal waters and gases. Prolonged exposure to elemental mercury released from geothermal facilities may induce neurologic disorders. To assess this risk, we derived an estimate of the lifetime probability of muscle tremors based on four epidemiological studies. 
The lifetime risk of exhibiting tremors was calculated to be $1.2 \times 10^{-6}$ as a result of exposure to mercury emitted from the reference $100-\mathrm{MW}$ facility. For $3000 \mathrm{MW}$ of development in the Imperial Valley, we predicted 7.6 cases of mercury-induced tremors. The mean number of cases of tremors for the reference industry was calculated to be $55\left(2.75\right.$ per $\left.10^{18} \mathrm{~J}\right)$ and at the $95 \mathrm{th}$ cumulative percentile of population risk, 164 cases $\left(8.2\right.$ per $\left.10^{18} \mathrm{~J}\right)$.

- Exposure to radon and its short-lived daughters poses a risk of lung cancer. We calculated the probability of lung cancer from $30 \mathrm{y}$ of exposure to ${ }^{222} \mathrm{Rn}$ (in equilibrium with its daughters) to be $8 \times 10^{-6} \mathrm{~m}^{3} / \mathrm{pCi}$, using a basic risk factor of $5 \times 10^{-4}$ cases of lung cancer per working-level month (WLM). Operation of the reference $100-\mathrm{MW}$ geothermal facility results in risks of lung cancer ranging from $6.4 \times 10^{-7}$ to $2.4 \times 10^{-8}$ at distances of 10 and $80 \mathrm{~km}$ from the facility, respectively. A population risk of 0.5 cases of cancer was predicted for the $3000-\mathrm{MW}$ scenario in the Imperial Valley. The mean population risk of the reference $21,000-\mathrm{MW}$ industry was predicted to be 8.5 cases of lung cancer $\left(4.2 \times 10^{-1}\right.$ per $10^{18} \mathrm{~J}$ of electricity $) ; 26$ cases $\left(1.3\right.$ per $\left.10^{18} \mathrm{~J}\right)$ were predicted at the 95 th cumulative percentile of population risk.

- The ingestion of groundwater or surface water contaminated with arsenic derived from geothermal fluids could cause skin cancer. To determine an upper limit of skin cancer risk, we assessed the potential effects of directly discharging waste geothermal fluids to surface waters. The case we chose for analysis is the operation of the Wairakei geothermal power plant in New Zealand, which discharges all of its waste geothermal fluids to a local river. The discharges are estimated to produce a $39 \mu \mathrm{g} /$ liter increase in the arsenic concentration in the river, and we calculate the resulting lifetime risk of ingesting that contaminated water to be a surprisingly high $1.6 \times 10^{-2}$. That calculation is based on a lifetime probability of cancer equal to $4 \times 10^{-4}$ liter/ $\mathrm{gg}$, derived from epidemiological studies of Taiwanese exposed to elevated levels of arsenic in drinking water from wells. The risk estimate is probably incorrect for the following reasons: arsenic has been shown to be an essential element, and therefore the linear, no-threshold dose-response model is inapplicable; mammals have a detoxification mechanism of methylation; and arsenic concentrations in drinking water of up to $100 \mu \mathrm{g} /$ liter do not appear to result in excessive body burdens. 
The geothermal industry in this country is relatively young and as a consequence, various kinds of occupational health problems have arisen and then brought under control by improved industrial hygiene practices. The occupational health data that are available reflect such changing conditions, and so these health statistics cannot be used to predict the occupational health effects of a full-scale industry. We therefore used rates of accidental deaths and occupational diseases from similar industries to estimate occupational risks. According to our calculations, there would be 14 accidental deaths per $10^{18} \mathrm{~J}$ of electricity and 340 occurrences of occupational diseases per $10^{18} \mathrm{~J}$.

\section{ECOLOGICAL EFFECTS}

We examined the potential effects of emissions of hydrogen sulfide and carbon dioxide on forest plants and crops and concluded that no negative effects on vegetation would occur. In fact, growth enhancement of plants is more likely than stress. We also analyzed the potential consequences of accidental releases of geothermal fluids onto vegetation and soils adjacent to power plants. Our calculations show that less than 5 ha of land will be affected by inadvertent releases--assuming that berms and sumps are not used to contain the spilled fluids. 


\section{HEALTH AND ENVIRONMENTAL EFFECTS \\ DOCUMENT ON GEOTHERMAL ENERGY--1981}

\section{ABSTRACT}

We assess several of the important health and environmental risks associated with a reference geothermal industry that produces $21,000 \mathrm{MW}$ for $30 \mathrm{y}$ (equivalent to $\left.20 \times 10^{18} \mathrm{~J}\right)$. The analyses of health effects focus on the risks associated with exposure to hydrogen sulfide, particulate sulfate, benzene, mercury, and radon in air and arsenic in water. Results indicate that emissions of hydrogen sulfide are likely to cause odor-related problems in 29 of 51 geothermal resources areas, assuming that no pollution controls are employed. For individuals living within an $80 \mathrm{~km}$ radius of the geothermal resources, chronic exposure to particulate sulfate (an oxidation by-product of hydrogen sulfide in the atmosphere) could result in between 0 to 95 premature deaths per $10^{18} \mathrm{~J}$ of electricity generated. The mean population risk of leukemia from the inhalation of benzene was calculated to be $3 \times 10^{-2}$ cases per $10^{18} \mathrm{~J}$; at the 95 th cumulative percentile of risk, $8.5 \times 10^{-2}$ cases per $10^{18} \mathrm{~J}$ were predicted. Exposure to elemental mercury in the atmosphere could produce between 0 and 8.2 cases of tremors per $10^{18} \mathrm{~J}$ of electricity. Inhalation of radon and its short-lived daughters poses a mean population risk of $4.2 \times 10^{-1}$ lung cancers per $10^{18} \mathrm{~J}$ and 1.3 cases per $10^{18} \mathrm{~J}$ at the 95 th cumulative percentile of risk. Our analysis of skin cancer risk from the ingestion of surface water contaminated with geothermally derived arsenic suggests that an existing linear, dose-response model is probably incorrect. It is inconsistent with data showing that arsenic is an essential element and that excessive body burdens do not appear even when arsenic reaches $100 \mu \mathrm{g} /$ liter in drinking water. We based our estimates of occupational health effects on rates of accidental deaths and occupational diseases in surrogate industries. According to our calculations, there would be 14 accidental deaths per $10^{18} \mathrm{~J}$ of electricity and 340 cases of occupational diseases per $10^{18} \mathrm{~J}$. The analysis of the effects of noncondensing gases on vegetation showed that ambient concentrations of hydrogen sulfide and carbon dioxide are more likely to enhance rather than inhibit the growth of plants. Finally, we studied the possible consequences of accidental releases of geothermal fluids and concluded that probably less than 5 ha of land would be affected by such releases during the production of $20 \times 10^{18} \mathrm{~J}$ of electricity. 


\section{INTRODUCTION}

Geothermal energy is heat stored within the earth's crust. This source of energy has been used to produce electricity on a commercial basis in the U.S. since 1960, and the installed electric generating capacity is now over $900 \mathrm{MW} \mathrm{e}^{\cdot}$ For comparison, the energy potential of identified geothermal resources is estimated to be about $23,000 \mathrm{MW}$ for $30 \mathrm{y}$, and unidentified resources could be more than three times as great. ${ }^{1}$ As this energy industry expands to higher levels of power production, its cumulative health and environmental risks could become significant, perhaps unacceptable. Accordingly, a basic purpose of this Health and Environmental Effects Document (HEED) is to quantitatively assess such risks and to determine whether they are manageable. Another important objective of the HEED is to identify areas of research that can lead to improved estimates of health and environmental effects.

Geothermal resources usually exist as either convective or conductive heat flow systems. In both systems most of the heat is stored in the rock matrix. Heat transfer within convective systems is primarily through the circulation of water or steam in porous or fractured geologic media. The heat source for these so-called hydrothermalconvection systems is often a shallow, magmatic intrusion. ${ }^{2}$ Hydrothermal systems are subcategorized as vapor-dominated (steam) or hot-water systems. Vapor-dominated systems such as The Geysers in northern California are the easiest to utilize for the production of electricity as the tapped steam can be sent directly to a low-pressure turbine. Hot-water systems with temperatures greater than $150^{\circ} \mathrm{C}$ can be used to generate electricity with currently available technology; however, the conversion process is more complex because the geothermal liquid must be flashed to produce steam. ${ }^{3}$ Lower temperature systems $\left(\sim 90\right.$ to $150^{\circ} \mathrm{C}$ ) are usable for other purposes such as space heating and other nonelectric or direct uses.

Two examples of conductive geothermal systems are geopressured and hot dry rock resources. Geopresssured resources exist as deep sedimentary formations containing hot, saline liquid at pressures considerably higher than normal hydrostatic. The value of these resources is enhanced by the presence of natural gas dissolved in the fluids. The extraction of geopressured energy is not a demonstrated technology at this time. Most of the development activities associated with this resource have focused on characterization of the resource in the Gulf Coast region. Hot dry rock resources refer to low permeability, high-temperature granitic, metamorphic, or cemented sedimentary formations that are usually in contact with a young magmatic intrusion. Heat transfer from the intrusion is strictly by conduction. To exploit hot dry rock resources, fractures 
are artificially created in the formation by hydraulic fracturing, and then water is circulated through the fracture zone, heated, and returned to the surface where the heat is extracted for electricity production or direct uses. ${ }^{4}$ This method of resource extraction is under active research and development, but it is not considered a near-term technology.

The geothermal resource area with the largest amount of electrical energy generation in the world is located at The Geysers. Here, the first $11-\mathrm{MW}$ unit began operating in 1960, and today 15 units with a net capacity of $908 \mathrm{MW}$ are in operation. Hot-water resources, in contrast, have been developed much more slowly, and only two 10-MW $\mathrm{W}_{\mathrm{e}}$ power plants are now operating in California's Imperial Valley. In the long term, however, hot-water resources offer a far greater potential for power production. The energy potential of identified hot-water resources is estimated to be the equivalent of $21,000 \mathrm{MW}$ e generated for $30 \mathrm{y}$, compared with the less than 2,000 MW $\mathrm{e}$ generated for $30 \mathrm{y}$ at The Geysers--the only vapor-dominated resource area in the U.S. outside of the National Parks. ${ }^{1}$ Here we address the potential effects of developing the large energy potential of the hot-water resources.

\section{OVERVIEW OF POTENTIAL HEALTH AND ENVIRONMENTAL EFFECTS}

There are several health and environmental issues connected with the extraction of hot water or steam from geothermal reservoirs and the subsequent processing to generate electricity. Based on measurements and experience at existing geothermal facilities and wells, the most serious concerns for both types of resources relate to emissions of gases that are not condensed at operating temperatures and pressures. The chemical composition of these gases varies widely from reservoir to reservoir; however, the major constituent is typically carbon dioxide, and significant amounts of methane and hydrogen sulfide are nearly always present along with trace amounts of benzene, radon, and mercury. Exposure to atmospheric concentrations of hydrogen sulfide, benzene, radon, and mercury pose potential hazards to public and occupational health. In addition, exposure to hydrogen sulfide and toxic chemicals used in hydrogen sulfide abatement systems has been identified as an occupational health hazard. ${ }^{5}$ Environmentally, noise emissions have been a problem at The Geysers due to venting of high-pressure steam at wellheads and generating units. ${ }^{6}$ Issues more applicable to the development of hot-water resources include the disposal of large volumes of spent geothermal liquids, accidental spills of fluids, land subsidence caused by the withdrawal of fluids, and enhanced seismicity from fluid injection or reservoir cooling. In addition, phytotoxic effects to 
vegetation in the vicinity of power plants can be caused by cooling tower emissions of water droplets (i.e., drift) containing toxic substances derived from steam condensate used as cooling water. 7

The primary focus of this HEED on geothermal energy is on atmospheric emissions of noncondensing gases because we believe these gases pose the greatest hazard to public and occupational health. We also consider ecological effects caused by accidental spills of geothermal fluids and emissions of hydrogen sulfide. In subsequent years other HEEDs will address some of the other potentially important effects such as subsidence and cooling tower drift.

\section{METHODOLOGY}

The basic methodology we use to assess the risks of geothermal power production is outlined in Fig. 1. To begin with, we define the basic attributes of the reference energy industry including the level of energy production to be assessed; the relevant characteristics of energy conversion technologies; and importantly, the potential releases of pollutants from geothermal facilities. Next, the transport and fate of the pollutants released into the environment are simulated by media-specific (i.e., air and water) models. Estimates of the environmental concentrations of contaminants are then used in dose-response models to determine effects on vegetation, animals, and man. The occupational health effects associated with geothermal energy are evaluated using occupational health data along with exposure estimates and effects models. Finally, special models or analytical techniques are used to simulate nonpollutant effects associated with noise emissions, subsidence, and seismicity. Another component of the assessment methodology is the quantification of the uncertainty or the accuracy of our estimates of health and environmental effects. 


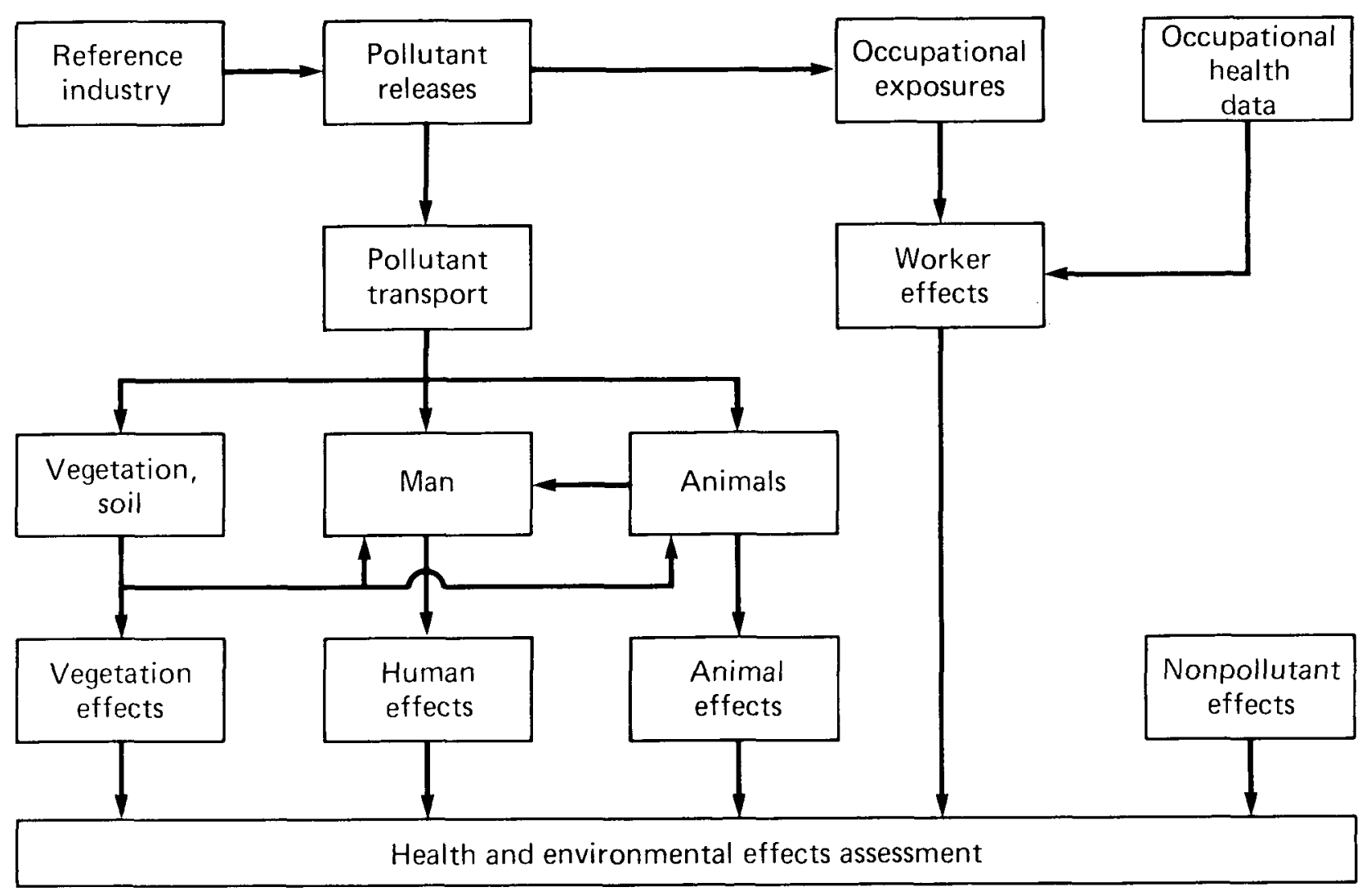

FIGURE 1. Conceptual diagram of the methodological approach of performing the health and environmental effects assessment of geothermal energy. 


\section{THE REFERENCE GEOTHERMAL POWER INDUSTRY}

Geothermal power production is projected to grow steadily in the years ahead. Most of the new generating facilities will rely on the proven, vapor-dominated resources of The Geysers, but substantial development is also expected to occur at the more prevalent hot-water resource areas. The energy potential of the discovered hot-water resources is estimated to be $21,000 \mathrm{MW}$ for $30 \mathrm{y}$, compared with an estimated undiscovered resource base of over $72,000 \mathrm{MW}$ for $30 \mathrm{y} .^{1}$ We will consider the reference industry--at full development it will consist of power plants with an installed capacity equivalent to the 30-y power potential of the discovered resources (i.e., 21,000 $\mathrm{MW}$ ). There are currently 51 identified resource areas in 11 western states, with estimated energy potentials ranging from 23 to $3400 \mathrm{MW}$ for $30 \mathrm{y}$. Over $99 \%$ of the resources are found in the eight states shown in Fig. 2. Emission rates of pollutants from the power plants that comprise the reference industry will vary according to the chemical and physical characteristics of the 51 resource areas as well as the types of power plants installed. The ensuing discussion, therefore, begins with a brief review of the geothermal energy technologies addressed in the risk assessment followed by analyses of published data on the chemistry of noncondensing gases.

\section{GEOTHERMAL POWER TECHNOLOGIES}

The two basic types of geothermal power cycles that are being developed for commercial applications are flashed-steam and binary-fluid. A simple flashed-steam system is depicted in Fig. 3. Geothermal fluid is withdrawn from a well and afterwards steam is separated (i.e., flashed) from the extracted fluid by pressure reduction. The residual geothermal liquids are disposed of (usually by subsurface injection) while the separated steam is sent to a turbine. Steam exhausted from the turbine is condensed, creating enough water to meet the cooling water needs of the facility. Noncondensing gases are normally ejected from the condenser and if necessary piped to an abatement system. At The Geysers, steam is extracted from a geothermal reservoir by wells and then sent directly to a turbine. Thus, power plants at The Geysers are essentially the same as flashed-steam facilities except for equipment needed to separate steam from geothermal fluids and the extra injection wells required to dispose of the waste fluids. The binary-fluid cycle (Fig. 4) does not use steam to drive a turbine; instead, down-hole pumps withdraw geothermal fluid from production wells and then the pressurized fluids are sent through a heat exchanger that heats and vaporizes a secondary working 


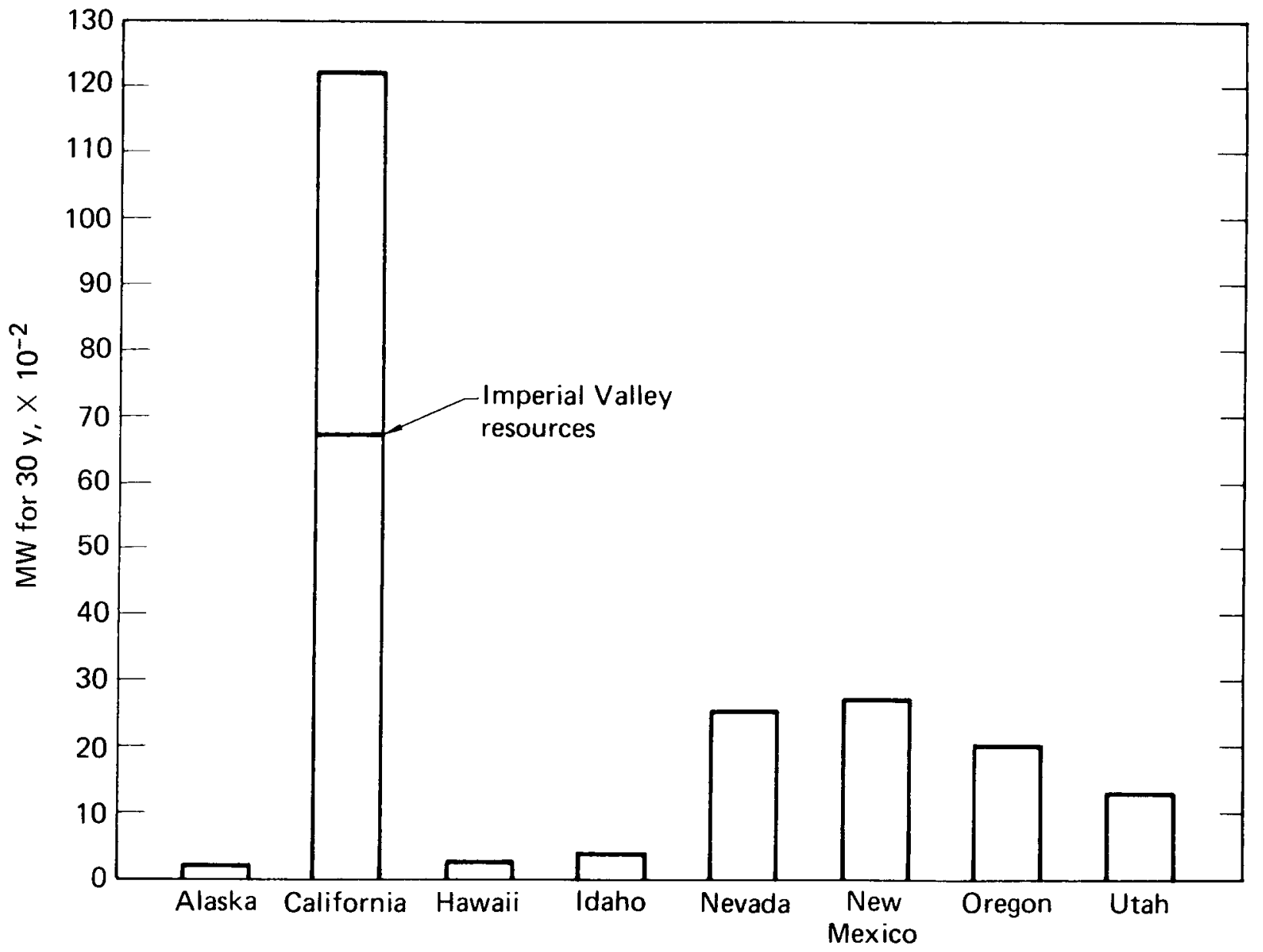

FIGURE 2. Electrical energy potentials for identified hot-water geothermal resources in eight western states. 1,8 Nearly a third of the total energy potential of the discovered resource base is associated with the resource of the Imperial Valley.

fluid (e.g., isobutane). The working fluid is subsequently expanded through a turbine, condensed, and reheated for another cycle. Spent geothermal fluids are disposed of by subsurface injection. One advantage of this type of power system is the absence of gaseous emissions so long as the geothermal fluids are kept at pressures high enough to prevent the volatilization of gases.' Moreover, binary-systems are capable of higher conversion efficiencies than flashed-steam facilities and consequently, smaller amounts of geothermal fluids are required per net unit of electricity generated. On the other hand, binary-fluid facilities must rely on external sources of cooling water because of the lack of steam condensate. 


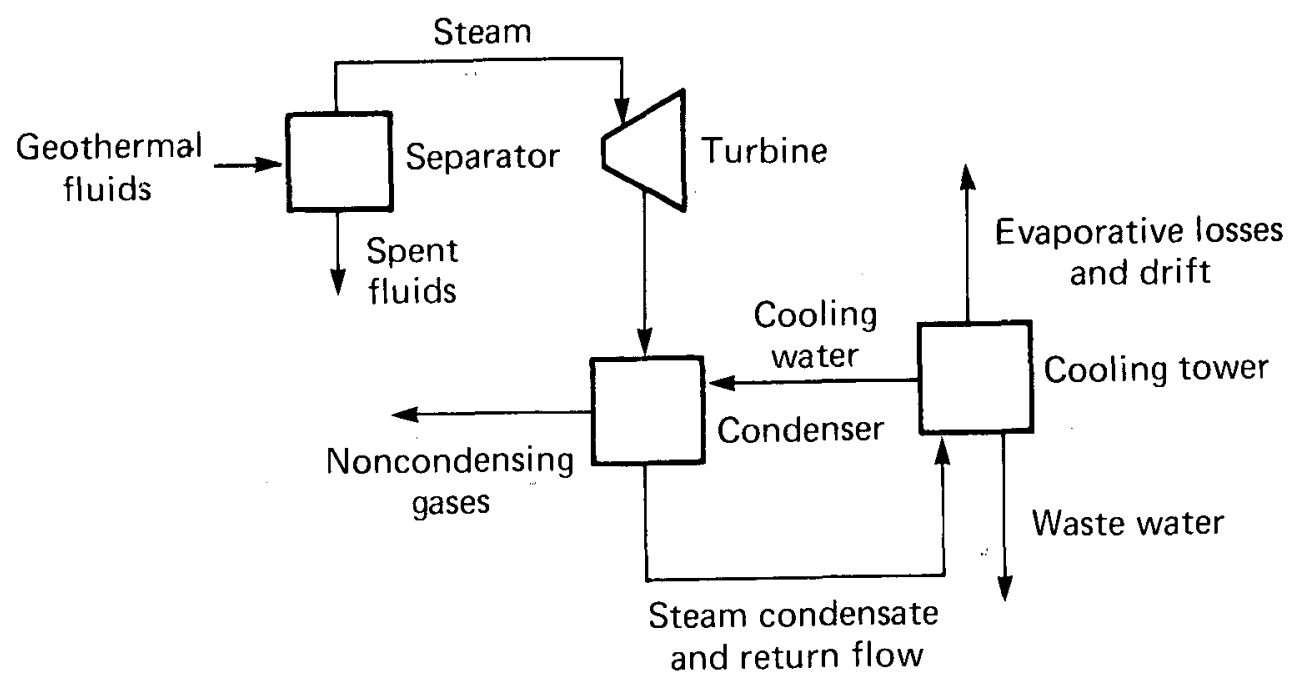

FIGURE 3. Single-stage, flashed-steam geothermal power cycle. Steam separated from the extracted geothermal fluids drives a turbine-generator to produce electricity. Noncondensing gases ejected from the condenser represent the most important pollutant release from this type of conversion technology (adapted from Layton and Morris ${ }^{7}$ ).

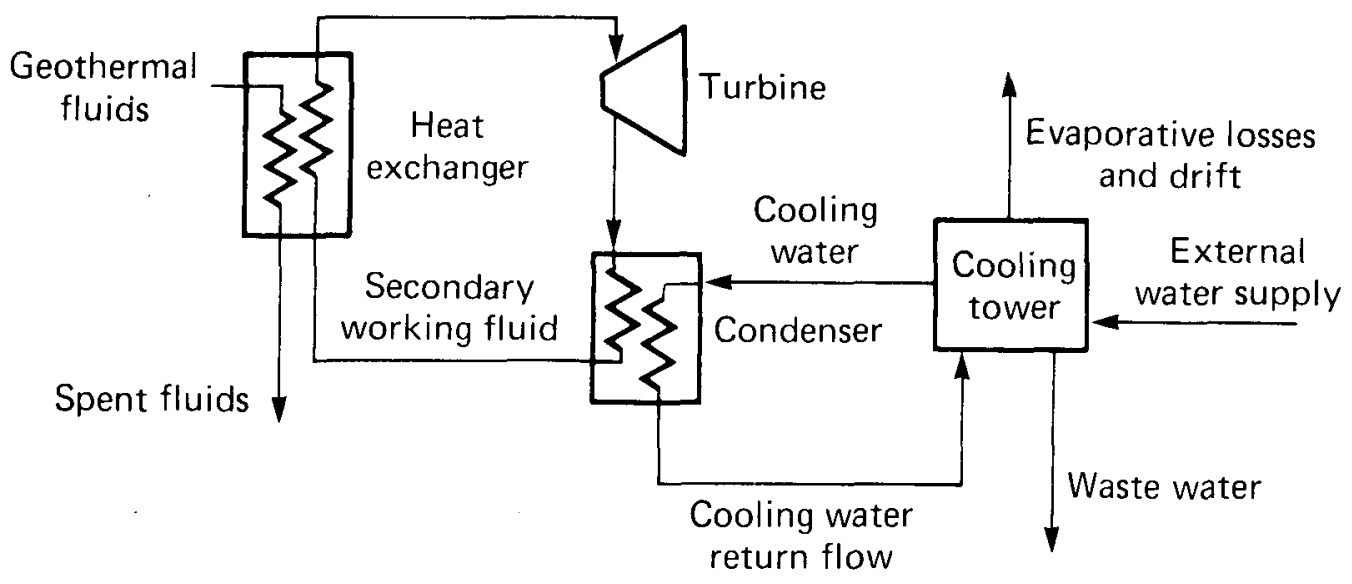

FIGURE 4. Binary-fluid power cycle. Geothermal fluids are sent through a heat exchanger that vaporizes a secondary working fluid, which in turn expands through a turbine-generator to produce electricity. Atmospheric emissions are not expected from this conversion technology so long as the extracted fluids are kept at pressures that prevent the dissolution of gases (adapted from Layton and Morris ${ }^{7}$ ). 
Aside from the design differences between the two conversion cycles, the primary determinant of resource requirements at a constant heat-rejection temperature is the temperature of the geothermal fluid. More precisely, as the temperature of a geothermal resource increases, the efficiency of converting the associated heat energy to electrical energy also increases, thereby reducing the demand for fluid. This relationship is important because the gaseous emissions from flashed-steam power plants are primarily a function of the fluid extraction rate and the concentration of noncondensing gases in the geothermal fluid. Therefore, the lowest gaseous emission rates would be from power plants utilizing high temperature resources containing low concentrations of dissolved gases. To estimate the fluid requirements of two-stage, flashed-steam power plants, ${ }^{*}$ we use the curve presented in Fig. 5, which is a power function fit of a curve presented in a simulation study by Pope et al. ${ }^{10}$ The fluid extraction rate is calculated from this equation:

$E=2.618 \times 10^{8} \mathrm{~T}^{-2.82}$,

where

$\mathrm{E}=$ fluid extraction rate, $\mathrm{kg} / \mathrm{net} \mathrm{kW} \mathrm{e}^{\bullet \mathrm{h} \text { and }}$
$\mathrm{T}=$ down-hole resource temperature, ${ }^{\circ} \mathrm{C}$.

Geothermal fluids from a well field are not usually transported more than a mile in order to minimize losses in temperature and pressure. Consequently, power plants will always be situated within the immediate vicinity of geothermal resource areas. This restriction is significant because it means that the environmental and health-related risks of an expanding geothermal power industry will depend heavily on the site-specific characteristics of the various resource areas (e.g., population density, fluid characteristics, etc.).

Subsurface injection of residual geothermal fluids is the final step in the relatively short geothermal fuel cycle. Injection is used to maintain reservoir pressures (which also provide some protection against subsurface compaction of sediments), to recover heat contained in reservoir rocks, and to dispose of waste fluids. The injection of waste fluids

\footnotetext{
* In a two-stage facility geothermal fluids discharged from the first steam separator are flashed a second time and the resulting steam is expanded through a low-pressure turbine.
} 


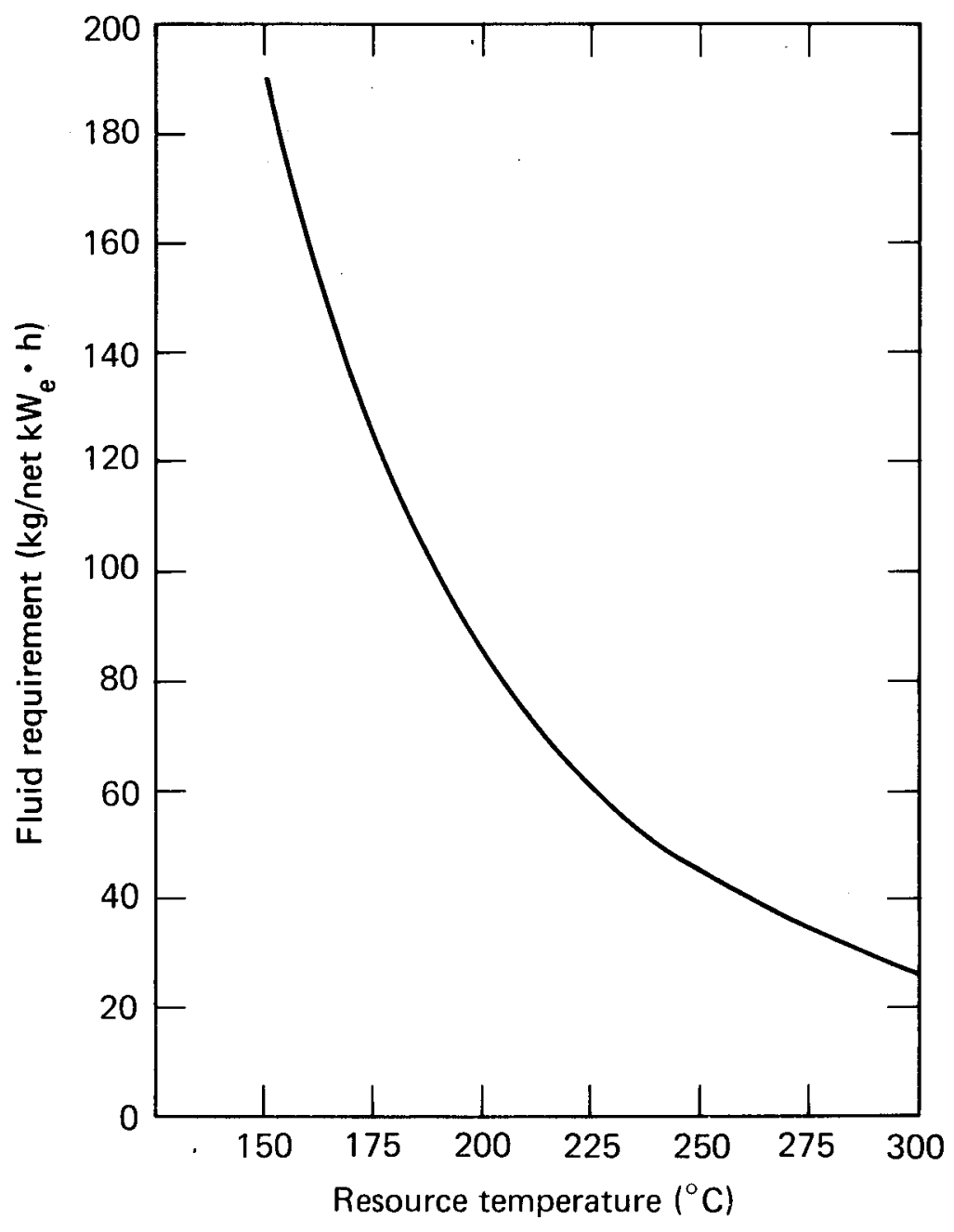

FIGURE 5. Geothermal fluid requirements versus resource temperature for a two-stage, flashed-steam power plant. This curve is a power function fit of a curve presented in a simulation study conducted by Pope et al. ${ }^{10}$

is actually a crucial pollution-control technology--for without it, geothermal power plants in the U.S. using hot-water resources would not be able to operate because of stringent water-quality regulations prohibiting the surface discharge of fluids containing toxic substances or having elevated temperatures. 


\section{CHEMISTRY OF NONCONDENSING GASES}

Geothermal fluids at depth are complex mixtures of dissolved gases and solids. As these fluids are withdrawn from a reservoir and processed to produce electricity in flashed-steam facilities, reductions in temperature and pressure cause the volatilization and subsequent release of various gases that do not condense at atmospheric temperatures and pressures. The major gases in the noncondensing gas phase normally consist of carbon dioxide (at around 90 mole \%), methane, hydrogen sulfide, ammonia, nitrogen, and hydrogen. Concentrations of those major gases as well as minor gases like benzene, mercury, and radon will vary among wells in the same geothermal resource area and they will also vary in time. ${ }^{11}$ In the following analyses we review data on concentrations and emissions of hydrogen sulfide, benzene, mercury, and radon--the most important gases from a health effects standpoint.

\section{Hydrogen Sulfide}

Hydrogen sulfide is found in nearly all high-temperature geothermal fluids (i.e., $>150^{\circ} \mathrm{C}$ ). It is probably formed by one or more of the following mechanisms: reaction of sulfur that is present in reservoir rocks with hot water, magmatic exhalation, or thermal metamorphism of marine sedimentary rocks. 11,12 Concentrations of this gas sampled from geothermal fluids in the U.S. range from 0.18 to $60.7 \mathrm{mg} / \mathrm{kg}$. Table 1 presents data on concentrations and emission rates of hydrogen sulfide from several water-dominated resource areas. Where published values were unavailable, the emission rates were determined by multiplying the concentrations of hydrogen sulfide in fluids by the fluid extraction rates calculated from the temperature-dependent function previously discussed. Table 1 also contains estimates of the uncontrolled emission rates of hydrogen sulfide from power plants at vapor-dominated resources (i.e., The Geysers and Larderello, Italy). To study the uncertainty of the measured concentrations and uncontrolled emission rates, we have prepared log-normal probability plots of the empirical cumulative distributions of hydrogen sulfide concentrations and emissions (see Figs. 6 and 7). The geometric mean $\mu_{g}$ of the U.S. data on hydrogen sulfide concentrations is $5.4 \mathrm{mg} / \mathrm{kg}$ with a geometric standard deviation $\sigma_{g}$ of 7.8. The emission data have a $\mu_{g}$ of $776 \mathrm{~g} / \mathrm{MW}_{\mathrm{e}} \cdot \mathrm{h}$ with a $\sigma_{\mathrm{g}}$ of 7.2 (data for Matsukawa, Japan were not used). 
Table 1. Concentrations of hydrogen sulfide in geothermal fluids and estimated emission rates for hot-water and vapor-dominated geothermal reservoirs in the U.S. and elsewhere.

\begin{tabular}{|c|c|c|c|}
\hline \multirow[b]{2}{*}{ Resource area } & \multicolumn{3}{|c|}{ Estimated emissions } \\
\hline & Concentration & $\left(g / M W_{e} \cdot h\right)$ & Reference \\
\hline \multicolumn{4}{|c|}{ in liquids ( $\mathrm{mg} / \mathrm{kg}$ ) } \\
\hline Salton Sea, California & 3.2 & $128^{a}$ & 13 \\
\hline Brawley, California & 55.1 & 2,424 & 14 \\
\hline Heber, California & 0.18 & 20 & 14 \\
\hline East Mesa, California & 0.54 & 60 & 13 \\
\hline Baca, New Mexico & 60.7 & 2,125 & 14 \\
\hline Roosevelt Hot Springs, Utah & 8 & 304 & 15 \\
\hline Long Valley, California & 14 & 826 & 16 \\
\hline Beowawe Hot Springs, Nevada & 6 & 348 & 17 \\
\hline Wairakei, New Zealand & $--^{b}$ & 570 & 18 \\
\hline A huachapan, El Salvador & 48 & 1,580 & 19 \\
\hline Otake, Japan & $--b$ & 542 & 19 \\
\hline Matsukawa, Japan & $--b$ & $5,050-20,800$ & 19 \\
\hline \multirow[t]{2}{*}{ Cerro Prieto, Mexico } & $--b$ & 32,000 & 18 \\
\hline & in steam (wt. \%) & & \\
\hline Larderello, Italy & $--\mathrm{b}$ & 14,300 & 19 \\
\hline The Geysers, California & 24.5 & 1,850 & 20 \\
\hline
\end{tabular}

a This emission rate has been recalculated.

b The hydrogen sulfide concentration associated with the emission rate was not reported. 


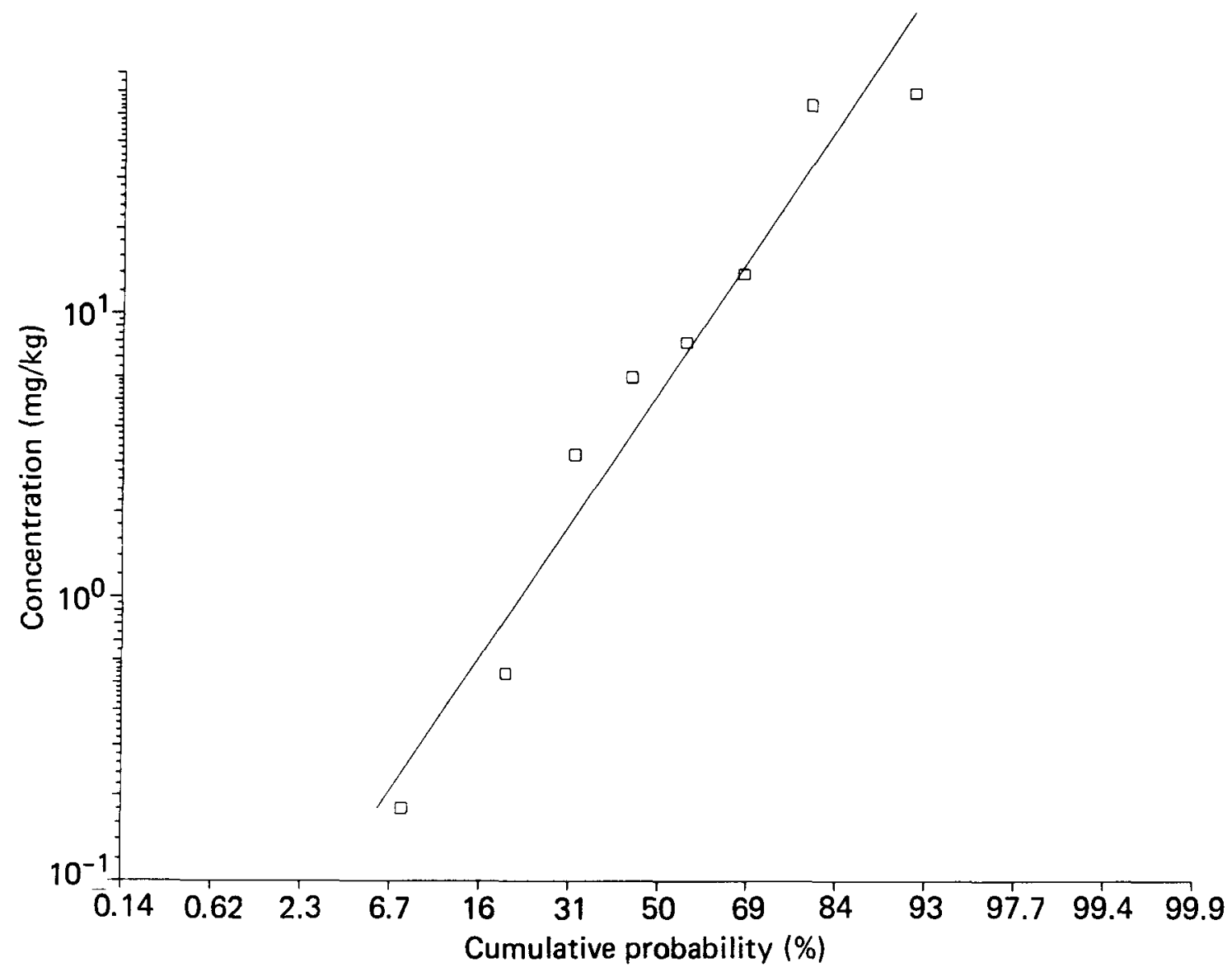

FIGURE 6. Log-normal probability plot of hydrogen sulfide concentrations in geothermal fluids from eight water-dominated resource areas in the U.S.

\section{Benzene}

Benzene is associated with the gas phase of fluids derived from geothermal reservoirs of sedimentary origin. Nonmethane hydrocarbon gases, including benzene, are thought to evolve from the thermal metamorphism of sediments containing organic matter. $^{21}$ Table 2 contains data on concentrations of benzene in noncondensing gases and estimated emission rates for a water-dominated geothermal resource and two vapor-dominated systems. Additional data on benzene are from Des Marais et al. who analyzed samples of dry or noncondensing gases from steam separators at Cerro Prieto, Mexico; steam wells at The Geysers in northern California; and thermal springs and fumaroles at Steamboat Springs in Nevada and at Yellowstone in Wyoming. ${ }^{25}$ Their analyses revealed benzene concentrations ranging from 0.1 to $15 \mathrm{ppmv}$. 


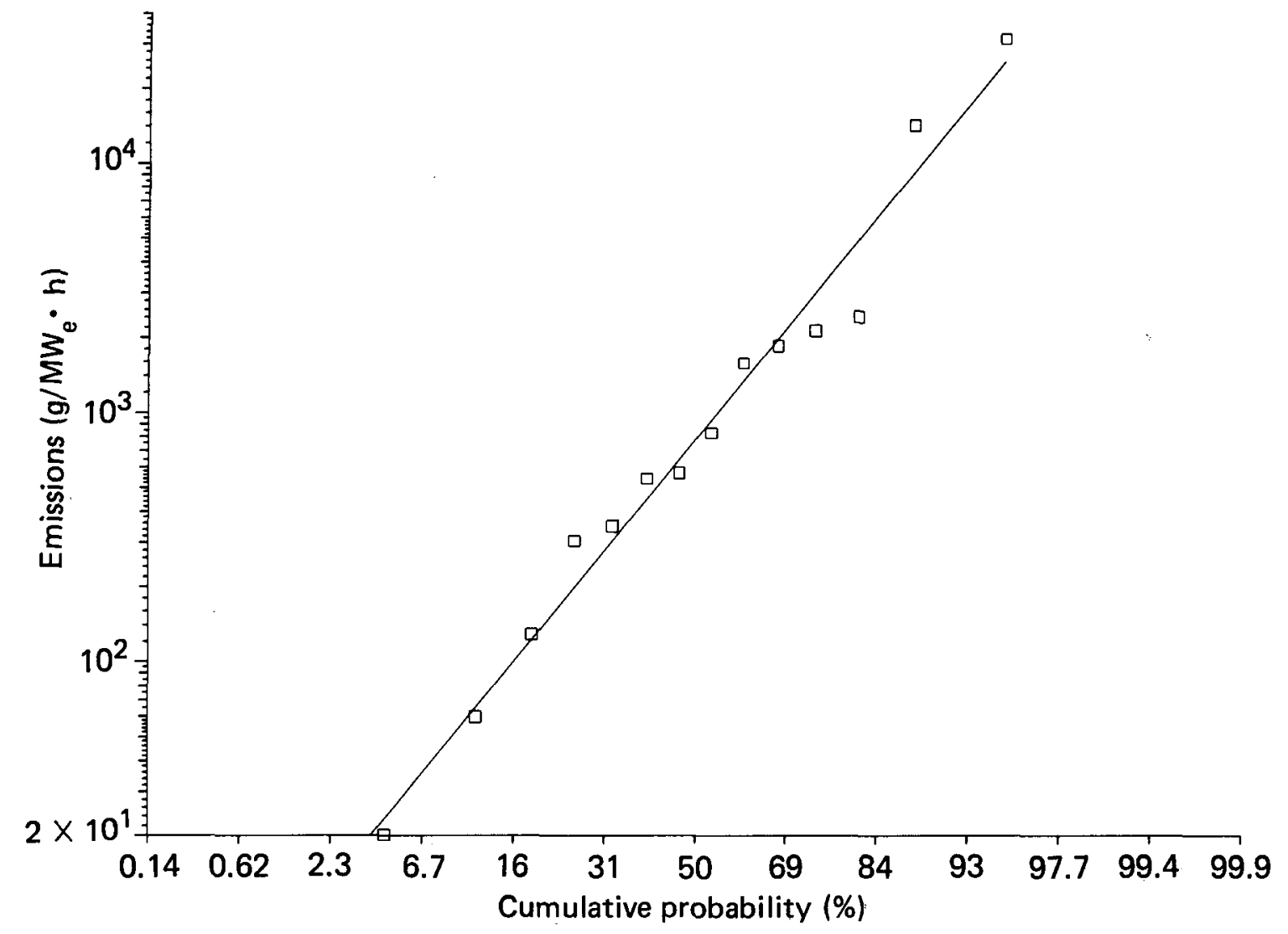

FIGURE 7. Log-normal probability plot of estimated emissions of hydrogen sulfide from 14 different resource areas in the U.S. and elsewhere in the world.

Based on the proposed relationship between rock type and occurence of hydrocarbon gases, we would expect gases from igneous-related geothermal systems to have much smaller levels of benzene or none at all because such systems are depleted in organic matter. Data developed by Nehring and Truesdell $^{26}$ support this hypothesis. Figure 8 shows chromatograms of gases they collected from igneous and sedimentary-related geothermal resources. As expected, the chromatograms of the gas samples from igneous areas in Kilauea, Hawaii and Steamboat Springs, Nevada (Figs. 8(a) and (b), respectively) have much lower quantities of organic gases than the samples from sedimentary and metamorphic rocks at The Geysers (Fig. 8(c)) and Cerro Prieto (Fig. 8(d)). In other supporting work, Des Marais et al. found that the ${ }^{13} \mathrm{C}$ content of hydrocarbon gases from the Cerro Prieto geothermal field were quite comparable to the ${ }^{13} \mathrm{C}$ content of coal found in drill cuttings from wells located in that resource area. ${ }^{25}$ Furthermore, pyrolysis of that coal in the laboratory produced methane that had a ${ }^{13} \mathrm{C}$ content similar to that of the methane measured in the noncondensing gases from the geothermal field. 
Table 2. Concentrations of benzene in noncondensing gases and estimated emission rates for power plants in geothermal reservoirs of sedimentary origin.

\begin{tabular}{lccc}
\hline $\begin{array}{l}\text { Resource } \\
\text { area }\end{array}$ & $\begin{array}{c}\text { Concentration } \\
\text { (ppmv) }\end{array}$ & $\begin{array}{c}\text { Estimated } \\
\text { emissions }^{\mathrm{a}} \\
\left(\mathrm{g} / \mathrm{MW}_{\mathrm{e}} \cdot \mathrm{h}\right)\end{array}$ & Reference \\
\hline & $85-370^{\mathrm{c}}$ & $11-67$ & 22 \\
$\begin{array}{l}\text { East Mesa, California } \\
\text { The Geysers, California }^{\mathrm{d}}\end{array}$ & $0-45.5$ & $0-4$ & 23 \\
Larderello, Italy $^{\mathrm{d}}$ & $0.3-38$ & $0.17-76$ & 24 \\
\hline
\end{tabular}

a Emission rates were estimated from the benzene concentration and fluid requirements.

b Water-dominated resource.

C Concentration was originally reported as a wt\% in the geothermal fluid.

d Vapor-dominated resource.

\section{Mercury}

Mercury is often present in geothermal waters and gases. The most comprehensive studies on mercury emissions from geothermal power plants have been done by Robertson et al. ${ }^{27,28}$ Their measurements show that mercury is released from geothermal facilities in liquid and gaseous discharges. For example at the Cerro Prieto power plant, where one set of measurements was made, approximately $90 \%$ of the mercury initially dissolved in extracted geothermal fluids was vaporized at the steam separator and entered the power plant with the incoming steam. The principal chemical form of the mercury vapor was elemental mercury (about $90 \%$ as $\left.\mathrm{Hg}^{\circ}\right)^{29}$ At the power plant, over half of the mercury condensed with the steam and was subsequently released to the atmosphere via the cooling tower ( $\sim 80 \%$ ); most of the remainder ( $220 \%$ ) was emitted through the gas ejector that removes noncondensing gases from the condenser. A small percentage of mercury was also released in the waste water discharged from the cooling tower. Measurements of mercury fluxes at electrical generating units at The Geysers (units 3, 7, 8, and 11) produced somewhat different results. The mass balances for those units also indicated that the cooling tower was the primary atmospheric release point for the mercury, but the remaining mercury was not fully accounted for by either the ejector emissions or 

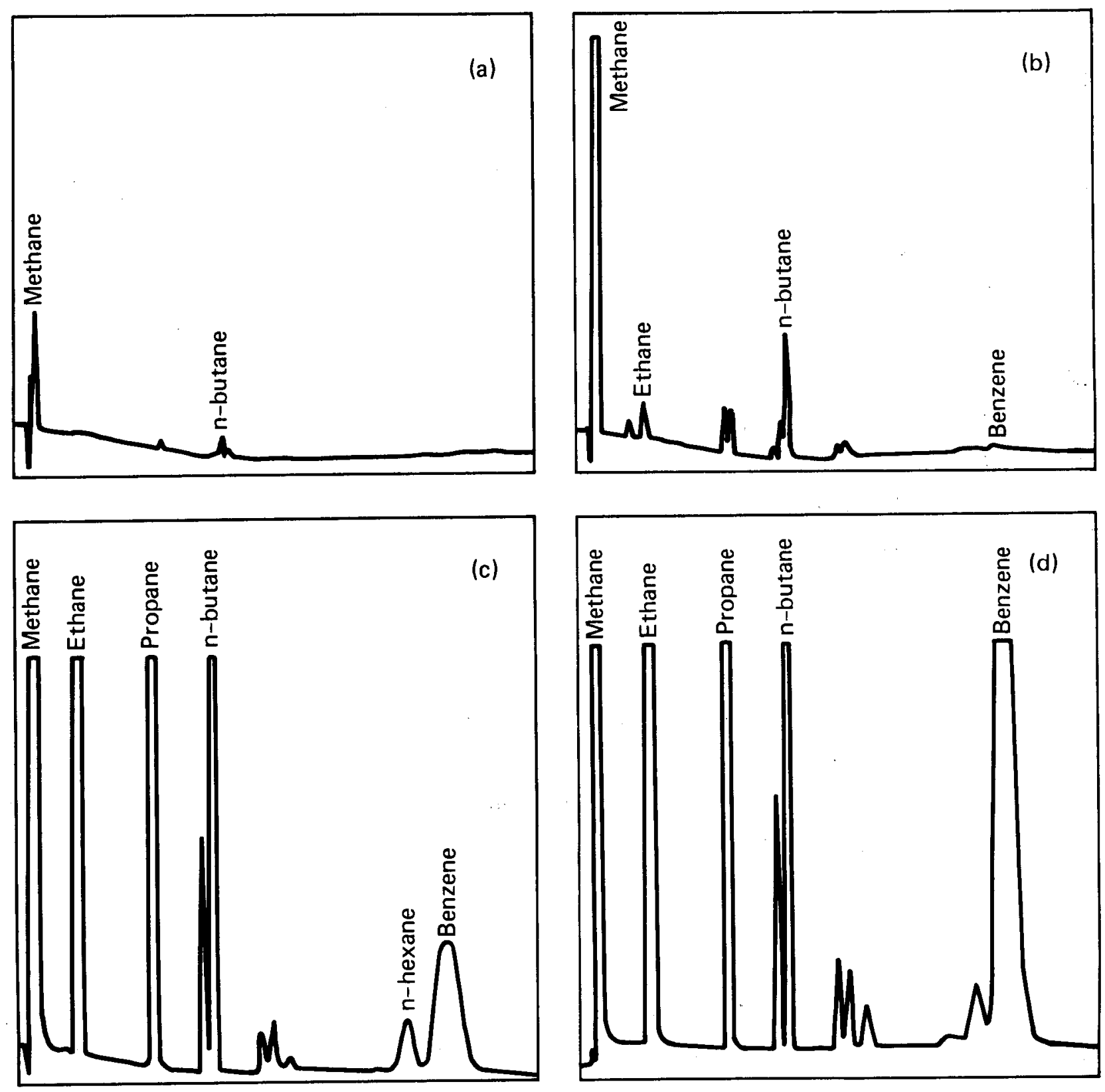

FIGURE 8. Chromatograms of gas samples from igneous-related geothermal systems ((a) Kilauea, Hawaii and (b) Steamboat Springs, Nevada) and from geothermal reservoirs composed of sedimentary and metamorphic rocks ((c) The Geysers, California and (d) Cerro Prieto, Mexico). Adapted from Nehring and Truesdell. 26 
discharges of waste water from the cooling tower. However, sludge in the basin of the cooling tower contained 0.02- to 0.2-wt\% mercury, and Robertson et al. believe that precipitation of mercury within the basin is an important removal mechanism. ${ }^{27}$ Table 3 contains data on elemental mercury concentrations and estimated emission rates for water-dominated systems. A log-normal probability plot of the concentration data is shown in Fig 9. The $\mu_{\mathrm{g}}$ of the concentrations is $0.003 \mathrm{mg} / \mathrm{kg}$ and the $\sigma_{\mathrm{g}}$ is 1.7 .

Table 3. Elemental mercury in geothermal fluids and estimated emission rates from four water-dominated resource areas.

\begin{tabular}{lclc}
\hline $\begin{array}{l}\text { Resource } \\
\text { area }\end{array}$ & $\begin{array}{c}\text { Estimated } \\
(\mathrm{ppbv})\end{array}$ & $\begin{array}{c}\text { emissions }^{\mathrm{a}} \\
\left(\mathrm{g} / \mathrm{MW}_{\mathrm{e}} \cdot \mathrm{h}\right)\end{array}$ & Reference \\
\hline Salton Sea, California & 18 & 0.05 & 13 \\
East Mesa, California & 6 & 0.54 & 13 \\
Puna, Hawaii & 3.4 & 0.1 & 17 \\
Cerro Prieto, Mexico & 2.5 & 0.07 & 28 \\
\hline
\end{tabular}

a Emission rates are based on the following assumptions: $90 \%$ of the total mercury dissolved in geothermal fluids is released to the atmosphere and of that amount, $90 \%$ is elemental mercury.

$\underline{\text { Radon }}$

Radon $\left({ }^{222} \mathrm{Rn}\right)$, a radioactive gas with a half-life of $3.8 \mathrm{~d}$, is a daughter product of the decay chain of naturally occurring ${ }^{238} \mathrm{U}$. After radon is formed from the decay of ${ }^{226} \mathrm{Ra}$ in near-surface soils and rocks, it diffuses to the atmosphere at rates that are dependent on ${ }^{226} \mathrm{Ra}$ activity, soil properties, meteorological conditions, and soil moisture. $^{30}$ At The Geysers, exhalation rates have been measured that range from $2.6 \times 10^{-6}$ to $150 \times 10^{-6} \mathrm{pCi} / \mathrm{m}^{2} \cdot \mathrm{s}^{31}$ Similar rates have been measured elsewhere in the world. ${ }^{32}$ Radon produced deeper in the Earth's crust may never reach the surface because ${ }^{222} \mathrm{Rn}$ can dissolve in groundwater where it decays to its daughter 


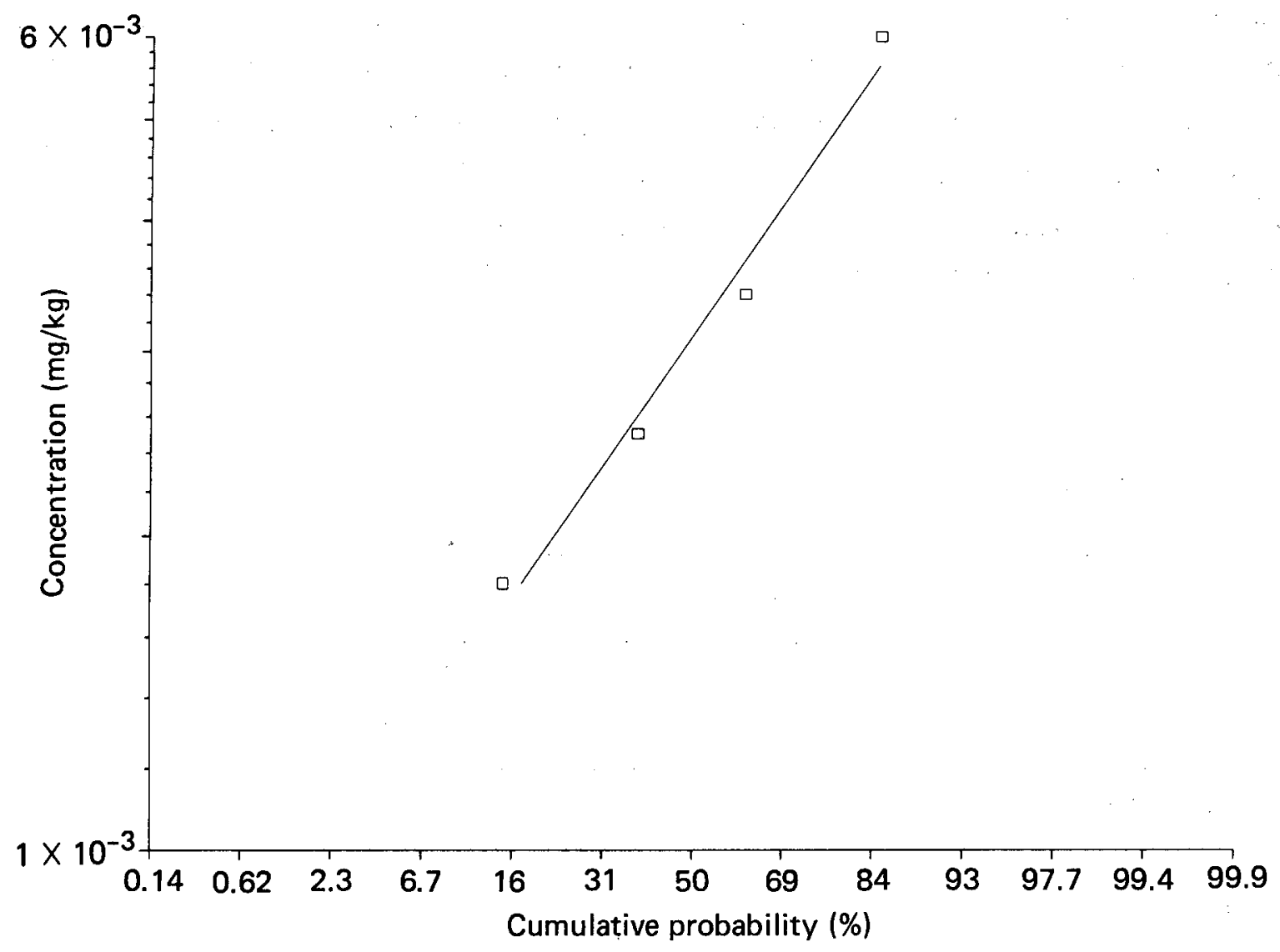

FIGURE 9. Log-normal probability plot of mercury concentrations in geothermal fluids from four water-dominated resource areas.

radionuclide ${ }^{218} \mathrm{Po}$, or the rate of diffusion is so slow with respect to its radioactive decay rate that virtually all of the gas is converted by the time it reaches the near-surface environment.

The radioactive decay of ${ }^{226} \mathrm{Ra}$ within a geothermal reservoir will produce ${ }^{222} \mathrm{Rn}$ that is dissolved in the geothermal fluids. When those fluids are extracted for power production, the ${ }^{222} \mathrm{Rn}$ will volatilize in a steam separator and the gas will eventually be released to the atmosphere along with the other noncondensing gases. In the Imperial Valley, ${ }^{222} \mathrm{Rn}$ levels range from $480 \mathrm{pCi} / \mathrm{kg}$ of geothermal fluid at the East Mesa resource area to $810 \mathrm{pCi} / \mathrm{kg}$ at the Salton Sea resource area. ${ }^{13}$ These values are consistent with those obtained from a study conducted by O'Connell and Kaufman in which 118 different geothermal waters were sampled for radon. 33 The log-normal probability plot for these data is shown in Fig. 10. The $\mu_{\mathrm{g}}$ of the data is $508 \mathrm{pCi} /$ liter of geothermal fluid, with a $\sigma_{\mathrm{g}}$ of 3.7 . 


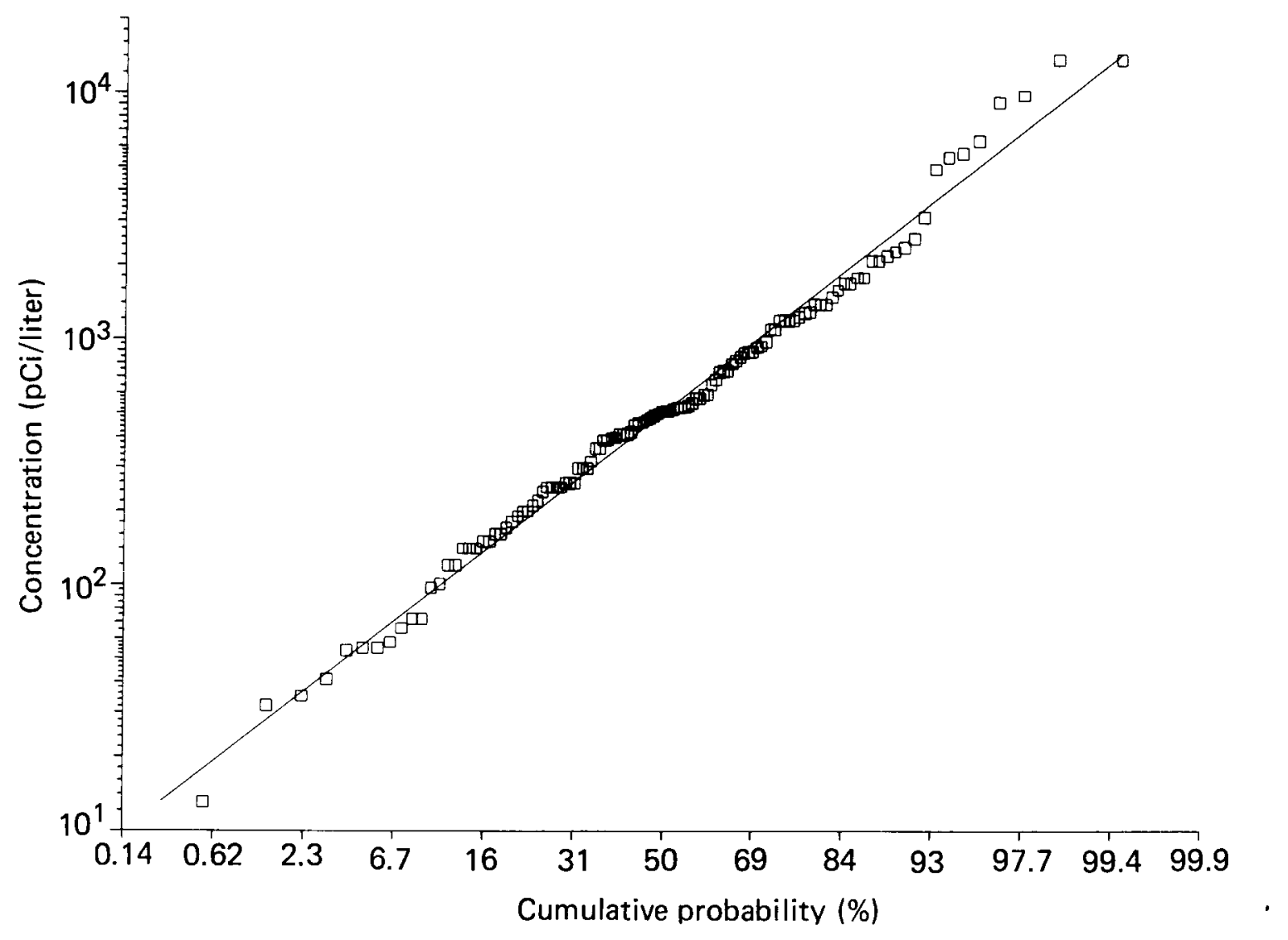

FIGURE 10. Log-normal probability plot of ${ }^{222} \mathrm{Rn}$ concentrations in 118 different geothermal waters in the western U.S. Data from O'Connell and Kaufman. ${ }^{33}$ 
A mature geothermal power industry will result in health risks both to workers in the industry and to the general public. The primary source of public health risks is the inhalation of toxic gases emitted by geothermal power plants. As noted earlier, the most important gases in this regard are hydrogen sulfide, benzene, mercury, and radon. Hydrogen sulfide emissions can cause noxious odors; sulfur oxides from the atmospheric oxidation of hydrogen sulfide can produce negative health effects including premature death; benzene is leukemogenic; radon is carcinogenic; and mercury can cause neurologic disorders. A secondary exposure pathway is the ingestion of surface waters or groundwaters contaminated with toxic substances (e.g., arsenic) derived from spent geothermal fluids. Although we are fairly confident that the toxic substances listed above are the only significant ones from a health effects standpoint, we cannot rule out the possibility that some new pollutant will be discovered in the process streams or that a recognized pollutant will later be shown to be much more hazardous than previously recognized. ${ }^{34}$ An example of this is benzene.

Prior to 1978, when Nehring and Truesdell published results of their analyses of the organic gas composition of noncondensing gases from geothermal systems, ${ }^{26}$ benzene was not one of the gases that was routinely assessed in environmental analyses of geothermal projects because there was no reason to expect its presence. Even now, measurements of nonmethane hydrocarbon gases are not available for most geothermal resources. Occupational risks associated with geothermal development have historically been associated with exposure to toxic levels of hydrogen sulfide. Abatement of hydrogen sulfide to reduce emissions of that gas has led to a secondary occupational health problem: exposure to toxic substances used in the abatement equipment.

\section{PUBLIC HEALTH}

Our purpose here is to quantify the various public health risks for a mature geothermal energy industry with a capacity of $21,000 \mathrm{MW} e^{\cdot}$ The assessments of health risks resulting from emissions of noncondensing gases focus on the risks of single power plants, a scenario representing geothermal development of $3000 \mathrm{MW} e$ in California's Imperial Valley, and a generic assessment for development at other resource areas using normalized risk values (e.g., risk per pollutant emission rate). The Imperial Valley was chosen for the detailed analysis because there is an abundance of background meteorological data on the valley and atmospheric transport is not directly affected by 
complex terrain. Furthermore, the valley has the largest concentration of geothermal resources in the U.S. and it is an area that is likely to have rapid development. Results of the assessments on the toxic substances are expressed in terms of an individual's risk of manifesting a particular response (e.g., premature death, cancer, etc.) as well as population effects (e.g., excess deaths). We also examine the risk of incurring skin cancer from the ingestion of drinking water contaminated with arsenic originating from geothermal fluids. For that assessment we perform a worst-case analysis of the skin cancer risk due to drinking water from the Waikato River in New Zealand, which is contaminated by direct discharges of geothermal fluids from a power plant.

\section{Risk Assessment Model and Uncertainty Analysis}

An individual's risk of exhibiting a given health effect (e.g., death, cancer, etc.) from exposure to an atmospheric pollutant from a geothermal power plant is a function of personal exposure to that pollutant and the relationship between exposure and the probability of effect. In our assessments of public health risks, we use a multiplicative model with linear terms that has the following mathematical form:

$\mathrm{R}=\mathrm{C} \cdot \mathrm{E} \cdot \frac{\mathrm{X}}{\mathrm{Q}} \cdot \mathrm{P}$,

where

$\mathrm{R}=$ an individual's lifetime risk of an effect resulting from exposure to the pollutant,

$\mathrm{C}=$ concentration of pollutant in geothermal fluid,

$E=$ extraction rate of geothermal fluid,

$\frac{X}{Q}=$ annual-average ambient concentration of pollutant per unit emission rate, and

$\mathrm{P}=$ probability of an effect due to unit pollutant exposure.

Another multiplicative term could be added to the model (i.e., $x e / \chi$ ) that relates the predicted outdoor or ambient concentration $\chi$ with an effective concentration $x e$ that represents the composite indoor and outdoor concentration an individual would be exposed to over a year. This term would be especially applicable to a pollutant like sulfur dioxide, which is usually higher in outdoor air than indoor air. ${ }^{35,36}$ However, because there are insufficient data on the indoor and outdoor concentrations for the pollutants we consider and on the life styles of residents in rural areas of the western U.S. where most of the geothermal resources are located, we assume by default that $x$ e equals $\chi$. 
An accurate prediction of an individual's risk of an adverse health effect resulting from exposure to a pollutant in the environment is often difficult to obtain because of uncertainties regarding estimates of exposure as well as the dose-response function for the pollutant being assessed. Therefore, it is helpful to quantify the uncertainties to gain a better understanding of how they affect the prediction of health risk: A simple method of incorporating uncertainty into the multiplicative assessment model is to assume that the parameters are log-normally distributed and they are independent. ${ }^{3,37,38}$ The uncertainties of the individual parameters can then be propagated to obtain an overall estimate of the uncertainty for the health risk by

$\operatorname{Var}(\ln R)=\operatorname{Var}(\ln C)+\operatorname{Var}(\ln E)+\operatorname{Var}\left(\ln \frac{X}{Q}\right)+\operatorname{Var}(\ln P)$

where for example,

$$
\begin{aligned}
\operatorname{Var}(\ln R) & =\ln ^{2} \sigma_{g}(R) \text { and } \\
\sigma_{g}(R) & =\text { geometric standard deviation of } R .
\end{aligned}
$$

The geometric standard deviation $\sigma_{g}$ for each parameter can be determined graphically or analytically; however, when sufficient data are absent, it must be determined judgmentally.

For cases where the model parameters are not log-normally distributed, different methods must be employed to analyze uncertainties. One method is to use Monte Carlo simulation (see, for example, Ref. 39). As described by Schwarz and Hoffman,

The Monte Carlo procedure randomly selects a set of parameter values from a prespecified distribution for each input parameter and calculates the model output for those values. This process is repeated many times for other sets of randomly selected parameter values. The distribution of the predictions of all iterations is considered to be an estimate of the distribution of the model output. 40

An alternative approach is to construct finite probability distributions (FPDs), which are truncated, discrete forms of continuous probability density functions (PDFs), that can be combined numerically on a computer to obtain an estimate of the PDF for the output of the model. With this method, each PDF is broken down into discrete probability intervals that are subsequently combined using probabilistic arithmetic to compute a PDF of the model output. The Monte Carlo technique, in contrast, calculates a distribution function of the model output that is a function of randomly selected parameter values.' In 
our assessments we employed the computer code MACROI developed by Edwards that enables a user to propagate FPDs that approximate continuous log-normal, normal, uniform, log-linear, and triangular PDFs. ${ }^{41}$

\section{Effects of Hydrogen Sulfide}

Atmospheric releases of hydrogen sulfide represent the most significant public health concern of geothermal energy production. Hydrogen sulfide is a toxic gas ${ }^{42}$; at concentrations above 1000 parts per million by volume (ppmv) it can cause respiratory paralysis and above $200 \mathrm{ppmv}$ this gas is still dangerous and should be recognized as an imminent threat to life. Olfactory paralysis takes place at concentrations of 150 to $250 \mathrm{ppmv}$ and consequently its characteristic odor becomes undetectable at life-threatening levels. ${ }^{34}$ The threshold for serious eye damage is between 50 and 100 ppmv.

Absorption of hydrogen sulfide through the lung or the gastrointestinal tract produces toxic effects that are believed to be caused by the reversible inhibition of cellular cytochrome oxidase by the undissociated form of hydrogen sulfide. ${ }^{42}$ However, hydrogen sulfide is detoxified in humans and animals by oxidation to benign sulfates. For example, guinea pigs can detoxify $85 \%$ of a single lethal dose of sulfide each hour. This gas is considered a noncumulative poison because of the detoxification mechanism and because of its reversible inhibition of enzyme systems. There is no evidence that indicates that hydrogen sulfide in air is carcinogenic, mutagenic, or teratogenic. 43

From a public health perspective, odor annoyance rather than the acute effects discussed above is the primary consequence of hydrogen sulfide emissions. The more severe effects are unlikely because atmospheric dispersion of the gas after release from a power plant will typically result in nontoxic, ground-level concentrations. Anspaugh and Hahn have reviewed the literature concerning the odor detection threshold of hydrogen sulfide. 5 With one exception, most of the studies they examined agreed fairly well and indicated that the median threshold for odor perception is about $0.005 \mathrm{ppmv}$. In addition, approximately $20 \%$ of the population can smell this gas at a concentration of 0.002 ppmv. There is also some evidence that chronic exposures to low levels of hydrogen sulfide may produce other health effects, primarily of a neurasthenic nature. For example, residents downwind of power units situated at The Geysers resource area have complained of headaches, nausea, sinus congestion, abrupt awakening, etc., when ambient levels were near 0.1 ppmv.

A primary issue therefore of geothermal energy development is the presence of undesirable odors in the vicinity of future generating facilities. In evaluating the potential for odor annoyance, we are basically concerned about the occurrence of short- 
term (i.e., $1 \mathrm{~h}$ or less) concentrations of hydrogen sulfide downwind from one or more power plants. Ermak et al. have shown that in order to avoid violations of the California hourly standard ${ }^{*}$ for hydrogen sulfide (i.e., $0.03 \mathrm{ppmv}$ ) from occurring beyond a distance of $1 \mathrm{~km}$ from a $100-\mathrm{MW}_{\mathrm{e}}$ geothermal power plant operating in the Imperial Valley, its emission rate would have to be $0.8 \mathrm{~g} / \mathrm{s}$ (equivalent to $30 \mathrm{~g} / \mathrm{MW} \mathrm{e} \cdot \mathrm{h}$ ). ${ }^{44}$ The California standard, however, is too high to prevent the odor of hydrogen sulfide from being detected by most people. At 0.03 ppmv more than $80 \%$ of the population would be able to detect its odor. At this point, a distinction should be made between odor detection and annoyance. It is conceivable that some individuals would not be bothered by slight odors (i.e., at their personal threshold levels) that occur only occasionally--other individuals, though, may be annoyed by the same infrequent odors. However, it appears that an ambient level of $0.03 \mathrm{ppm}$ (hourly average)--six times higher than the median, instantaneous threshold value--would result in odor problems, in part because elevated excursions ( 10 to $15 \mathrm{~min}$ ) during an hour could be particularly annoying.

An emission rate of nearly $1 \mathrm{~g} / \mathrm{s}$ from a single power plant (equivalent to $36 \mathrm{~g} / \mathrm{MW}$ e $\mathrm{h}$ from a $100-\mathrm{MW}$ facility) would lead to levels that are occasionally annoying since, according to the calculations of Ermak et al. for such a facility in the Imperial Valley, ambient concentrations of around $0.03 \mathrm{ppmv}$ would be expected at distances of up to a kilometer from the source. ${ }^{44}$ For comparison, future power plants at The Geysers, where the cumulative emissions of hydrogen sulfide from over $900 \mathrm{MW}_{\mathrm{e}}$ of geothermal energy development are a continuing environmental concern, may have to limit emissions to $0.6 \mathrm{~g} / \mathrm{s}^{45}$ In summary, it appears that emission rates from generating facilities may have to be kept below $1 \mathrm{~g} / \mathrm{s}$ to avoid unwanted odors.

To estimate the magnitude of potential odor-related problems of the reference geothermal energy industry, we calculated the emission rates for single power plants in each of the 51 resource areas, based on the assumption that all of the geothermal fluids contain $0.7 \mathrm{mg} / \mathrm{kg}$ of hydrogen sulfide. That concentration represents the $16 \mathrm{th}$ percentile on the log-normal probability plot of the cumulative distribution of the hydrogen sulfide concentrations previously discussed (see Fig. 6). Even with that low concentration, nearly $60 \%$ of the resource areas still would have one or more generating facilities with uncontrolled emission rates exceeding $1 \mathrm{~g} / \mathrm{s}$.

\footnotetext{
* The California standard was originally set to protect against odor annoyance, but it was based on a study that had anomalously high detection thresholds as compared with other studies (see Ref. 34).
} 
Hydrogen sulfide released from a geothermal power plant will oxidize in the atmosphere to sulfur dioxide, which is then oxidized to sulfate aerosols. The human health effects of exposure to sulfur oxides have been examined in numerous laboratory and epidemiological studies (see, for example, Ref. 46). Studies dealing with the acute effects of inhalation of sulfur oxides generally indicate that these effects are unlikely at the ambient levels expected to occur as a result of the atmospheric oxidation of hydrogen sulfide. Our interest, therefore, is in the health response to long-term exposure to low concentrations of sulfur oxides--specifically, an individual's risk of premature death. Epidemiological studies such as those carried out by Mendelsohn and Orcutt 47 and Lave and Seskin ${ }^{48}$ suggest that the inhalation of particulate sulfates rather than sulfur dioxide is a primary source of health risks associated with long-term, low-level exposure to polluted air. Work done by Amdur showing that sulfate aerosols are a respiratory irritant $^{49}$ would seem to support their findings. On the other hand, the epidemiological studies are unable to determine whether sulfate, which could actually be correlated with some other unmeasured, potentially toxic contaminant like respirable particles, is truly the cause of the health effects (i.e., deaths). For this risk analysis, we follow Wilson et al. who suggest that sulfate respresents a reasonable surrogate or substitute measure of the health hazard of exposure to polluted atmospheres containing sulfur oxides and particles until further health effects research is completed. 50

Health Risks of a Single Facility. More than half of the identified resource areas have energy potentials that are below $150 \mathrm{MW}_{\mathrm{e}}$ for $30 \mathrm{y}$, and consequently single power plants with generating capacities of $150 \mathrm{MW}$ or less could conceivably be used to develop these resources. ${ }^{*}$ Our analysis of the health risks of sulfate exposure resulting from the atmospheric oxidation of hydrogen sulfide emitted from a single power plant is based on a $100-\mathrm{MW}$ e flashed-steam facility operating with these reference conditions: the hydrogen sulfide concentration $C$ in the geothermal fluids processed is $5.4 \times 10^{-3} \mathrm{~g} / \mathrm{kg}$ and the extraction rate $E$ is $1900 \mathrm{~kg} / \mathrm{s}$. The extraction rate is based on a weighted average value of the rates (in $\mathrm{kg} / \mathrm{MW}_{\mathrm{e}}$ - s) for flashed-steam power plants located in all of the resource areas. We employed a Gaussian diffusion model developed by Ermak and Nyholm ${ }^{51}$ to calculate the annual, ground-level concentrations of sulfate $(X)$ around the reference facility.

\footnotetext{
* Most geothermal facilities will probably have generating capacities less than $100 \mathrm{MW} \mathrm{e}^{\text {, }}$ but larger facilities at Wairakei, New Zealand $\left(150 \mathrm{MW}_{\mathrm{e}}\right)$ and Cerro Prieto, Mexico

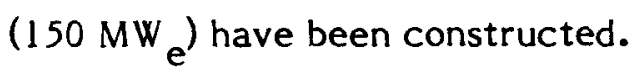


The model can simulate the conversion of hydrogen sulfide to sulfur dioxide and then to sulfate as well as the deposition of all three species onto the ground. The model was run with meteorological data (i.e., joint probability of wind speed, wind direction, and atmospheric stability) measured at a location in the central part of the Imperial Valley. A conversion rate of $1.48 \times 10^{-5} / \mathrm{s}$ was used to represent the oxidation of hydrogen sulfide to sulfur dioxide 52 and a rate of $2.78 \times 10^{-6} / \mathrm{s}$ was used to represent the oxidation of sulfur dioxide to sulfate. ${ }^{53}$ The deposition velocity of hydrogen sulfide was taken to be $2 \times 10^{-4} \mathrm{~m} / \mathrm{s}$ after Judeikis and Wren ${ }^{54}$; a value of $1 \times 10^{-2} \mathrm{~m} / \mathrm{s}$ was used for sulfur dioxide ${ }^{55}$; and finally, the deposition rate of sulfate aerosols was set equal to $1 \times 10^{-3} \mathrm{~m} / \mathrm{s}^{56}$ Simulation of the atmospheric diffusion, conversion, and deposition out to a radius of $80 \mathrm{~km}$ from the plant showed a fairly uniform distribution of sulfate, averaged over 16 wind sectors. The sector-averaged values of $x / Q$ at $10 \mathrm{~km}$ increments ranged from a high of $2.6 \times 10^{-4} \mu \mathrm{g} \cdot \mathrm{s} / \mathrm{m}^{3} \cdot \mathrm{g}$ at 10 to $20 \mathrm{~km}$ from the source to a low of $1.8 \times 10^{-4} \mu \mathrm{g} \cdot \mathrm{s} / \mathrm{m}^{3} \cdot \mathrm{g}$ at $80 \mathrm{~km}$. The weighted average value over the $80 \mathrm{~km}$ radius was $2 \times 10^{-4} \mathrm{\mu g} \cdot \mathrm{s} / \mathrm{m}^{3} \cdot \mathrm{g}$. For our estimate of $\mathrm{P}$, the probability of premature death from exposure to particulate sulfate, we used a value of $3.5 \times 10^{-5} \mathrm{~m}^{3} / \mathrm{hg} \cdot \mathrm{y}$, which is from a review made by Wilson et al. of existing epidemiological studies. 50

Some clarifying comments relating to the value of $\mathrm{P}$ should be mentioned here. First, we have implicitly assumed that at low levels of ambient sulfate, the dose-response function is linear with no threshold of effects. If the curve is actually concave at low doses or if it has a threshold, this assumption will lead to over-estimates of health risk. It is interesting to note, however, that the epidemiological studies by Mendelsohn and Orcutt $^{47}$ and Lave and Seskin ${ }^{48}$ do support the linearity assumption. Nevertheless, inadequacies in the epidemiological studies (e.g., uncontrolled confounding factors such as cigarette smoking, inaccurate air-quality measurements, etc.) could conceivably act together to obscure the nature of the relationship between sulfate exposure and premature death. Indeed, at low concentrations sulfate exposure may not cause negative health effects.

Table 4 summarizes the values of the parameters employed in the sulfate risk analysis and the corresponding geometric standard deviations for a case in which all of the parameters are log-normally distributed. Using these values, we calculate a median risk of sulfate-induced death $\mathrm{R}$ to be $7.2 \times 10^{-8} / \mathrm{y}$ for persons living within a radius of $80 \mathrm{~km}$ from a $100-\mathrm{MW}$ e power plant. The $\sigma_{\mathrm{g}}$ for $\mathrm{R}$ is about 11 , and thus the upper and lower limits to the estimated $68 \%$ confidence interval are $7.9 \times 10^{-7} / \mathrm{y}$ and $6.5 \times 10^{-9} / \mathrm{y}$. In our previous discussion on the possible effects of hydrogen sulfide emissions, we indicated that emissions from geothermal facilities may have to be under $1 \mathrm{~g} / \mathrm{s}$ to avoid odors near plants. At that emission rate, the median health risk associated with a $100-\mathrm{MW}$ e facility becomes $7 \times 10^{-9} / \mathrm{y}$. 
Table 4. Estimates of the log-normal parameters used in the risk assessment of sulfate exposure associated with the operation of a 100-MW

\begin{tabular}{clcc}
\hline Parameter & Units & $\begin{array}{c}\text { Geometric mean } \\
\mu_{\mathrm{g}}\end{array}$ & $\begin{array}{c}\text { Geometric standard } \\
\text { deviation } \sigma_{\mathrm{g}}\end{array}$ \\
\hline $\mathrm{C}$ & $\mathrm{g} / \mathrm{kg}$ & $5.4 \times 10^{-3}$ & $7.8^{\mathrm{a}}$ \\
$\mathrm{E}$ & $\mathrm{kg} / \mathrm{s}$ & $1.9 \times 10^{3}$ & $1.5^{\mathrm{b}}$ \\
$\mathrm{X} / \mathrm{Q}$ & $\mu \mathrm{g} \cdot \mathrm{s} / \mathrm{m}^{3} \cdot \mathrm{g}$ & $2 \times 10^{-4}$ & $2.5^{\mathrm{C}}$ \\
$\mathrm{P}$ & $\mathrm{m}^{3} / \mathrm{Mg} \cdot \mathrm{y}$ & $3.5 \times 10^{-5}$ & $2^{\mathrm{b}}$ \\
\hline
\end{tabular}

a Derived from the log-normal probability plot of $\mathrm{H}_{2} \mathrm{~S}$ concentrations (see Fig. 6).

b Determined judgmentally.

C Based in part on a validation study by Draxler. 57

We reassessed the uncertainty of the health risk for sulfate exposure by replacing the log-normal distributions previously used to describe the uncertainty of the parameters $E$ and $\mathrm{P}$ with triangle and uniform FPDs, respectively. A triangular distribution is a better approximation of the true distribution of the weighted average extraction rate because in reality that rate is limited by resource temperatures, which are nearly all between $150^{\circ} \mathrm{C}$ and $300^{\circ} \mathrm{C}$. The log-normal distribution, on the other hand, would include all extraction rates from zero to plus infinity. The minimum and maximum values we selected for the triangle distribution were 9 and $28 \mathrm{~kg} / \mathrm{MW}_{\mathrm{e}} \cdot \mathrm{s}$, with a median value of $19 \mathrm{~kg} / \mathrm{MW}_{\mathrm{e}}{ }^{\bullet} \mathrm{s}$. We chose a uniform distribution for values of $P$ that go from $1 \times 10^{-8}$ to $1 \times 10^{-4} \mathrm{~m}^{3} \mathrm{Ag} \cdot \mathrm{y}$. This type of distribution was selected because it does not result in a preferential probability for any particular value of $P$ in the range noted above--including a value representing a negligible or essentially zero effect of sulfate exposure (i.e., $\left.1 \times 10^{-8} \mathrm{~m}^{3} / \mathrm{hg} \cdot \mathrm{y}\right) .^{*}$ The median value of $\mathrm{R}$ becomes $6.3 \times 10^{-8} / \mathrm{y}$ for uncontrolled emissions from a $100-\mathrm{MW}_{\mathrm{e}}$ facility compared with the previously calculated value of $7.2 \times 10^{-8} / \mathrm{y}$. At a cumulative probability of 0.95 , the corresponding value of $\mathrm{R}$ in the revised estimate is $3.3 \times 10^{-6} / \mathrm{y}$, whereas the value at that cumulative probability for the log-normal case was $3.6 \times 10^{-6} / y$.

* The MACROI code is restricted to distributions with nonzero, positive values. 
Health Risks of $3000 \mathrm{MW}(\mathrm{e})$ in the Imperial Valley. In this analysis we examine the sulfate-related health risks of developing $3000 \mathrm{MW}$ for $30 \mathrm{y}$ at the Salton Sea, Brawley, Heber, and East Mesa geothermal resource areas in the Imperial Valley. Because the resource areas are located relatively close to each other, atmospheric emissions from each resource area will contribute to the total changes in air quality across the valley. This is the only place in the U.S. where increases in the ambient concentrations of noncondensing gases and the associated health risks are significantly affected by the operation of power plants in two or more adjacent resource areas. Table 5 contains the values we used for the unabated emission rates of hydrogen sulfide from $100-\mathrm{MW}_{\mathrm{e}}$ power plants plus the assumed generating capacities for each resource area. Ground-level concentrations of sulfate were simulated using the same conversion and deposition rates as in the single-source case along with site-specific meteorological data for each resource area. 58 The siting pattern of the power plants was from a previous study completed by Ermak. 59

Figure $11(\mathrm{a})$ presents the regional isopleths of the predicted concentrations of sulfate and the associated risks of premature death from chronic exposure to the atmospheric sulfate. Most of the risks fall in the range of $2 \times 10^{-6} / y$ to just over $4 \times 10^{-6} / y$. If hydrogen sulfide emissions are lowered to $1 \mathrm{~g} / \mathrm{s}$ to limit odor annoyances (except at the Heber resource area where power plant emissions are already below $1 \mathrm{~g} / \mathrm{s}$ ), the risk levels fall to between $1 \times 10^{-7} / y$ and $2 \times 10^{-7} / y$ (see Fig. $11(b)$ ). For the case of uncontrolled emissions of hydrogen sulfide, we calculated a population exposure of $4.6 \times 10^{3} \mu \mathrm{g} \cdot$ persons $/ \mathrm{m}^{3}$ for residents of nine municipalities in the valley, representing over $80 \%$ of the valley's population. The population exposure for the controlled case was $2.9 \times 10^{2} \mu \mathrm{g} \cdot$ persons $/ \mathrm{m}^{3}$. The associated population risks for those two cases were 0.16 and 0.01 excess deaths per year, respectively. Over $30 \mathrm{y}$ the corresponding number of deaths would be 4.8 and 0.3 .

Cumulative Health Risks. An FPD for R, the number of premature deaths expected for the reference industry, was calculated by multiplying the FPDs of $C, x / Q$, and $P$ (see Table 4) and a fourth variable equal to the sum of the product of the extraction rates of geothermal fluids and the number of persons at risk (those living within an $80 \mathrm{~km}$ radius of a resource area) for each of the 51 resource areas. We assumed that this last variable is normally distributed having a mean of $3.9 \times 10^{10} \mathrm{~kg}$ - persons $/ \mathrm{s}$ and a standard deviation of $9.7 \times 10^{9} \mathrm{~kg} \cdot$ person/s. With $21,000 \mathrm{MW}$ of energy production and no control of hydrogen sulfide emissions, the mean number of premature deaths each year is predicted to be 23; at the 95th cumulative percentile, there are 64 premature deaths per year. In contrast, the mean rate of premature deaths would be reduced to about $0.3 / y$ (at 
Table 5. Uncontrolled emission rates of hydrogen sulfide from 100-MW flashed-steam power plants and total generating capacities used for the risk assessment of $3000 \mathrm{MW}$ of development in California's Imperial Valley.

\begin{tabular}{lccc}
\hline $\begin{array}{l}\text { Resource } \\
\text { area }\end{array}$ & $\begin{array}{c}\text { Generating } \\
\text { capacity } \\
\left(\mathrm{MW}_{\mathrm{e}}\right)\end{array}$ & $\begin{array}{c}\text { Fluid removal } \\
\text { rate } \\
\left(\mathrm{kg} / \mathrm{kW}_{\mathrm{e}} \cdot \mathrm{h}\right)\end{array}$ & $\begin{array}{c}\text { Hydrogen sulfide } \\
\text { emission rate } \\
(\mathrm{g} / \mathrm{s})\end{array}$ \\
\hline Salton Sea & 1400 & 40 & 3.6 \\
Brawley & 600 & 44 & 67.3 \\
Heber & 700 & 111 & 0.6 \\
East Mesa & 300 & 111 & 1.7 \\
\hline
\end{tabular}

the 95th cumulative percentile, 0.8 premature deaths per year) if emissions of hydrogen sulfide are limited to $36 \mathrm{~g} / \mathrm{MW}_{\mathrm{e}} \cdot \mathrm{h}$ to minimize potential odor problems at the various resource areas. A potentially significant source of bias in the analysis of the cumulative health risk is the use of a single value of $x / Q$ for all resource areas. The amount of bias introduced by using the single value will depend primarily on the nature of the differences between the meteorological data for the Imperial Valley and the data for other locations of geothermal resources. The effects of rough terrain on atmospheric dispersion will also contribute to the bias.

\section{Effects of Benzene}

Benzene is a hematotoxin that can cause various blood disorders including anemia, leukopenia, and thrombocytopenia. In addition, it has been identified as a leukemogen. The primary sources of information on the relationship between benzene and leukemia have not been animal studies, but rather epidemiological studies of workers exposed to benzene. Studies by Aksoy et al. involving shoe workers in Turkey ${ }^{60}$ and Infante et al. involving workers in the U.S. rubber industry ${ }^{61}$ provide strong evidence that the chronic inhalation of benzene can lead to leukemia. 

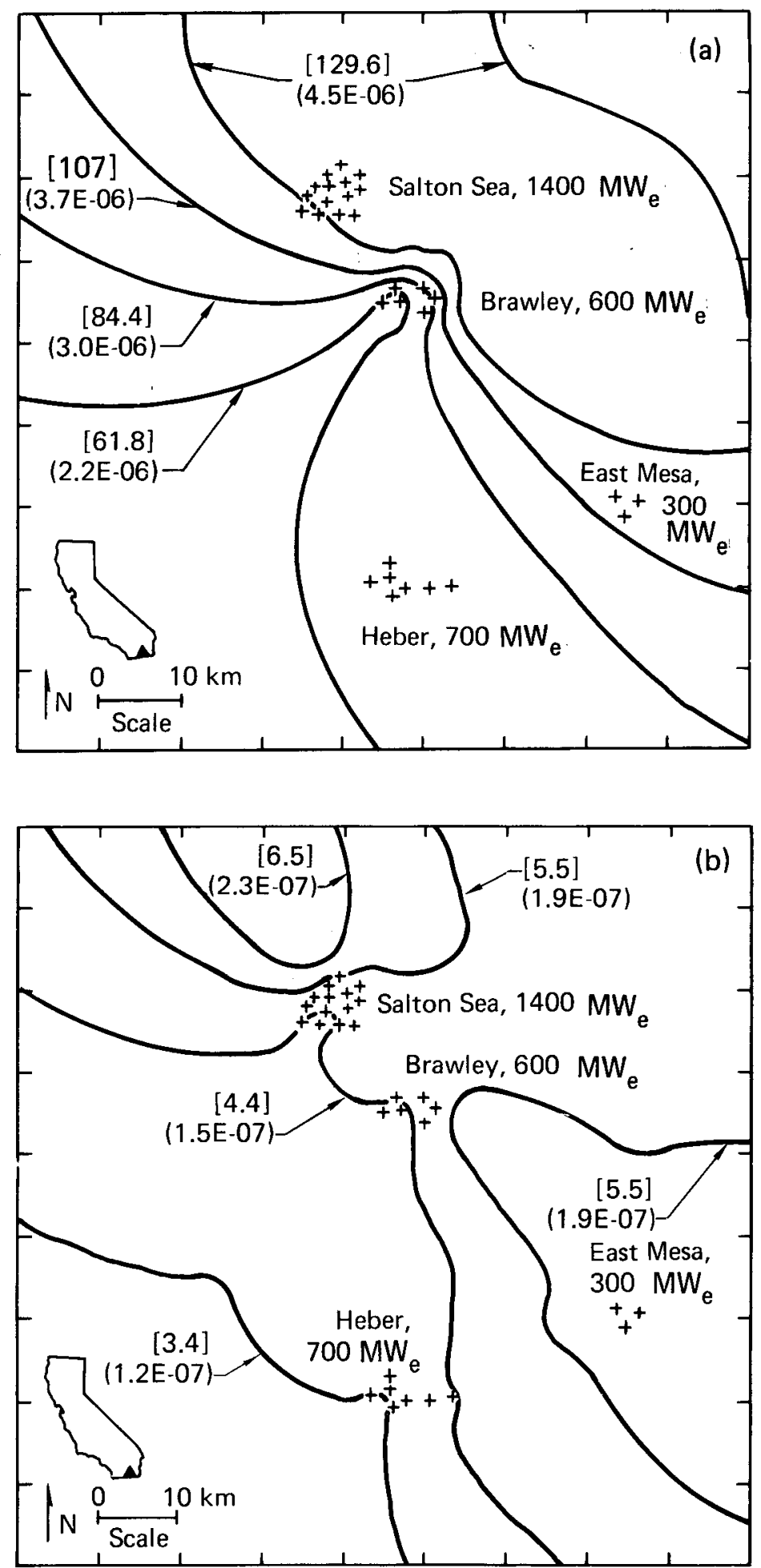

FIGURE 11. Isopleths of predicted sulfate concentrations and associated annual risks of premature death for a scenario of $3000 \mathrm{MW}_{\mathrm{e}}$ in the Imperial Valley: (a) no emission controls assumed and (b) emissions are controlled to $1 \mathrm{~g} / \mathrm{s}$, except at the Heber area where uncontrolled emissions are $0.6 \mathrm{~g} / \mathrm{s}$. Concentrations are in $\mathrm{ng} / \mathrm{m}^{3}$ (within brackets) and annual risks are expressed in machine notation (within parentheses). 
Health Risks of a Single Facility. Table 6 summarizes the parameter values used in the risk assessment of a single 100-MW facility. The value of $\mathrm{C}$ is based on the following assumptions: noncondensing gases from wells completed in geothermal reservoirs formed of sedimentary and/or metamorphic rocks have a $\mu_{\mathrm{g}}$ of $10 \mathrm{ppmv}$, the noncondensing gases are composed almost entirely of carbon dioxide, the noncondensing gases are $1 \%$ by weight in steam, and $0.2 \mathrm{~kg}$ of steam is produced per kilogram of geothermal fluid. The estimate of the lifetime probability of leukemia per average lifetime exposure to atmospheric benzene $P$ is the geometric mean of estimates of $P$ derived from three separate epidemiological studies. ${ }^{62}$ The sector-averaged values of $x / Q$ range from $0.08 \mu \mathrm{g} \cdot \mathrm{s} / \mathrm{m}^{3} \cdot \mathrm{g}$ at $10 \mathrm{~km}$ to $0.003 \mu \mathrm{g} \cdot \mathrm{s} / \mathrm{m}^{3} \cdot \mathrm{g}$ at $80 \mathrm{~km}$ (we assume that there is no deposition or conversion of benzene). Those concentrations must be converted to lifetime equivalent levels by multiplying them by $30 / 70$, the ratio of the number of years of geothermal energy production to the average life expectancy. The corresponding values of $R$ at distances of 10 and $80 \mathrm{~km}$ are approximately $2 \times 10^{-8}$ and $7 \times 10^{-9}$, respectively. The $\sigma_{\mathrm{g}}$ for the predicted risks of leukemia is 11 .

Health Risks of $3000 \mathrm{MW}(\mathrm{e})$ in the Imperial Valley. The only published data on benzene levels in geothermal fluids from the Imperial Valley are for two wells located at the East Mesa resource area. The benzene content in the noncondensing gases of the geothermal fluids that were sampled ranged from 0.015 to $0.065 \mathrm{wt} \%$ ( 85 to $370 \mathrm{ppmv}$ ). These values are considerably higher than benzene levels measured elsewhere (see the earlier discussion on benzene concentrations in noncondensing gases) and they should be verified. We therefore used the value of $C$ shown in Table 6 (i.e., $4 \times 10^{-5} \mathrm{~g} / \mathrm{kg}$ of geothermal fluid) to represent the typical concentration of benzene dissolved in geothermal fluids at East Mesa as well as the other resource areas. The emission rates for $100-\mathrm{MW}$ e power plants in the four resource areas are as follows: $0.12 \mathrm{~g} / \mathrm{s}$ for the Heber and East Mesa areas, $0.05 \mathrm{~g} / \mathrm{s}$ for Brawley, and $0.04 \mathrm{~g} / \mathrm{s}$ for Salton Sea (see Table 5 for the generating capacities and fluid removal rates used in the analysis of the $3000-\mathrm{MW}$ scenario). Essentially all of the lifetime risks of leukemia fell between $1.6 \times 10^{-6}$ (corresponding to a lifetime equivalent concentration of $0.2 \mu \mathrm{g} / \mathrm{m}^{3}$ ) and $1.6 \times 10^{-8}$ (at $\left.0.002 \mu \mathrm{g} / \mathrm{m}^{3}\right)$. The estimated number of premature deaths among residents of the valley's cities is 0.01 over $30 \mathrm{y}$.

Cumulative Health Risks. To calculate the cumulative health risks of exposure to benzene emitted from geothermal facilities at the 51 resource areas, we must make some simplifying assumptions. First, and foremost, we assume that the $\mu_{g}$ of benzene concentrations in geothermal fluids is $0.04 \mathrm{mg} / \mathrm{kg}$ with a $\sigma_{\mathrm{g}}$ of 8 , that is, the estimated 
Table 6. Estimates of the log-normal parameters used in the risk assessment of benzene exposure associated with the operation of a $100-\mathrm{MW}$ e power plant.

\begin{tabular}{cccc}
\hline Parameter & Units & $\begin{array}{c}\text { Geometric mean } \\
\mu_{\mathrm{g}}\end{array}$ & $\begin{array}{c}\text { Geometric standard } \\
\text { deviation } \sigma_{\mathrm{g}}\end{array}$ \\
\hline $\mathrm{C}$ & $\mathrm{g} / \mathrm{kg}$ & $4 \times 10^{-5}$ & 8 \\
$\mathrm{E}$ & $\mathrm{kg} / \mathrm{s}$ & $1.9 \times 10^{3}$ & 1.5 \\
$\mathrm{X} / \mathrm{Q}$ & $\mu \mathrm{g} \cdot \mathrm{s} / \mathrm{m}^{3} \cdot \mathrm{g}$ & 0.08 to 0.003 & 2.5 \\
$\mathrm{P}$ & $\mathrm{m}^{3} / \mathrm{\mu g}$ & $7.6 \times 10^{-6}$ & 1.8 \\
\hline
\end{tabular}

$68 \%$ confidence interval of the log-normal distribution is 0.005 to $0.32 \mathrm{mg} / \mathrm{kg}$. This assumption may well lead to high estimates of benzene emissions because it is based on data collected mainly from geothermal reservoirs composed of sedimentary and metamorphic rocks. We would expect the geothermal fluids associated with such reservoirs to have higher quantities of benzene than reservoirs composed of igneous, crystalline, or volcanic rocks (see the earlier discussion on benzene in the section dealing with the chemistry of noncondensing gases). A second assumption is that benzene emissions are not abated by pollution control systems used for the removal of hydrogen sulfide. With these assumptions in mind, we calculated the mean value of excess deaths over $30 \mathrm{y}$ to be 0.6; at the 95th cumulative percentile of the FPD for R, 1.7 deaths are predicted.

\section{Effects of Mercury}

The health effects of long-term exposure to airborne, elemental mercury have received far less scrutiny than the effects caused by the ingestion of foods (e.g., fish and seed grains) contaminated with the methylated form of mercury. ${ }^{63,64}$ Epidemiological studies of persons exposed to mercury vapors in their work environments have shown that mercury intoxication can manifest itself in several ways; for example, muscle tremors, psychosomatic disturbances, deterioration of intelligence, inflammation of the oral cavity, and lens discoloration. Such symptoms are rarely encountered nowadays because occupational exposures to mercury have been greatly reduced or eliminated by improved industrial hygiene practices. Mercury emissions from geothermal facilities are not likely to cause acute health effects; however, prolonged exposure to atmospheric mercury may 
cause subtle effects such as psychosomatic disturbances and finger tremors. ${ }^{65}$ Muscle tremors are the more reliable indicator of mercury poisoning, primarily because they are objectively verifiable. Using data from four studies of workers exposed to mercury, 66-69 we developed an estimate of the lifetime probability $P$ of manifesting such tremors due to the prolonged inhalation of ambient mercury.

Three of the studies on which our estimate of $P$ is based (see Table 7) give a breakdown of symptoms claimed or observed; in those instances we used the figures given for muscle tremors as the symptom of mercury intoxication. The fourth study (Kesic and Haeusler) simply reported the incidence of "outspoken symptoms of chronic mercury

Table 7. Epidemiological data used in the derivation of the dose-response function for elemental mercury.

\begin{tabular}{|c|c|c|c|c|c|c|}
\hline \multirow[b]{2}{*}{ Reference } & \multicolumn{2}{|c|}{ Concentration $\mathrm{Hg}^{\circ}\left(\mathrm{mg} / \mathrm{m}^{3}\right)$} & \multirow{2}{*}{$\begin{array}{l}\text { Mean } \\
\text { duration of } \\
\text { exposure }^{a} \\
\text { (y) }\end{array}$} & \multirow{2}{*}{$\begin{array}{l}\text { Sample } \\
\text { size }\end{array}$} & \multirow{2}{*}{$\begin{array}{c}\text { Cases of } \\
\text { observed } \\
\text { mercurialism }\end{array}$} & \multirow{2}{*}{$\begin{array}{l}\text { Equivalent } \\
\text { lifetime } \\
\text { exposure } \\
\left(\mu \mathrm{g} / \mathrm{m}^{3}\right)\end{array}$} \\
\hline & Range & $\operatorname{Mean}^{\mathrm{a}}$ & & & & \\
\hline \multirow[t]{2}{*}{66} & $0.18-0.38$ & 0.262 & 0.2 & 67 & $5^{\mathrm{b}}$ & 0.402 \\
\hline & & & 2.53 & 29 & $17^{b}$ & 4.819 \\
\hline \multirow[t]{3}{*}{67} & $0.07-0.88$ & 0.248 & 0.2 & 13 & $3^{b}$ & 0.326 \\
\hline & & & 1.22 & 13 & $6^{b}$ & 1.955 \\
\hline & & & 5.47 & 26 & $23^{b}$ & 8.473 \\
\hline $68^{C}$ & $0.25-1$ & 0.5 & 8.61 & 70 & 47 & 24.747 \\
\hline \multirow[t]{4}{*}{69} & $0.01-0.05$ & 0.022 & 5.47 & 276 & $40^{b}$ & 0.682 \\
\hline & $0.06-0.1$ & 0.077 & 5.47 & 145 & $45^{b}$ & 2.395 \\
\hline & $0.11-0.14$ & 0.124 & 5.47 & 61 & $57^{\mathrm{b}}$ & 3.844 \\
\hline & $0.24-0.27$ & 0.255 & 5.47 & 27 & $295^{b}$ & 7.905 \\
\hline
\end{tabular}


poisoning" with no breakdown, ${ }^{68}$ so we utilized the single figure reported. We conservatively assumed that the dose-response function for mercury is linear without an effects threshold because mercury has no known metabolic function and no human threshold has yet been demonstrated. ${ }^{70}$ Our estimate of $\mathrm{P}$ was calculated as the geometric means of the individual $P$ values weighted by the sample sizes of the four studies. Expressed mathematically,

$P=\prod_{i=1}^{4}\left(P_{i}\right)^{S_{i}}=0.07 \mathrm{~m}^{3} / \mu g$

where

$P_{i}=$ ratio of the incidence of effects reported in study $i$ to the lifetime exposure equivalent for the same study and

$S_{i}=$ ratio of sample size in study $i$ to the number of total samples in all four studies.

The above value for $\mathrm{P}$ is almost certainly too large. It would suggest for example that a resident of New York City, where ambient mercury is on the order of $0.01 \mathrm{\mu g} / \mathrm{m}^{3}$, faces a risk of 7 in 10,000 of developing mercury-induced tremors. One possible source of error, of course, is that humans may in fact have some dose-response threshold; another source is the body's clearance mechanism. In extrapolating public exposure-response curves from data on occupational or other exposures of limited duration, one must first convert the response to lifetime-exposure equivalents. The most conservative way to do this (and the way used in deriving the value of $\mathrm{P}$ above) is to assume response is entirely a function of the cumulative exposure independent of its time distribution. Thus

$\varepsilon_{1}=\varepsilon_{0} \cdot \frac{8 h}{24 h} \cdot \frac{240 \mathrm{~d}}{365 \mathrm{~d}} \cdot \frac{\mathrm{T}_{\mathrm{o}}}{\mathrm{A}_{\mathrm{o}}}$,

where

$\varepsilon_{1}=$ equivalent lifetime concentration of mercury to which an individual is exposed,

$\varepsilon_{o}=$ concentration of mercury in the workplace,

$\mathrm{T}_{\mathrm{o}}=$ duration of occupational exposure, and

$A_{0}=$ age of exposed worker. 
In fact, however, mercury is cleared from the body at some rate $\mathrm{C}$ such that

$$
B_{t}=\frac{D}{C}\left(1-e^{-C t}\right),
$$

where

$$
\begin{aligned}
& B_{t}=\text { body burden at time } t, \\
& D=\text { dose rate, and } \\
& C=\text { clearance rate. }
\end{aligned}
$$

Note that as $t$ increases, $B_{t}$ approaches $D / C$; at a sufficiently large $t$ therefore, $B_{t}$ reaches a virtual equilibrium. Unfortunately, while the clearance rate of elemental mercury is known for several organs, it is not known for the brain, the critical organ for chronic exposures. The available evidence suggests that it remains in the brain far longer than in other organs, with a halftime possibly as long as several years. 71 While it is probable therefore that the cumulative-exposure model overestimates the risk of inhaled mercury, we do not know by how much. However, since the rate of clearance from the brain is evidently much slower than the whole-body rate, we can at least estimate a lower bound for risk by setting the brain clearance rate equal to the body rate. With a value of $50 \mathrm{~d}$ for the whole-body halftime, ${ }^{71}$ the value of $\mathrm{P}$ is roughly an order of magnitude lower than the value based on the cumulative-dose model.

Health Risks of a Single Facility. The reference $100-\mathrm{MW}$ e power plant relying on geothermal fluids containing $0.003 \mathrm{mg} / \mathrm{kg}$ of elemental mercury will emit $4.6 \times 10^{-3} \mathrm{~g} / \mathrm{s}$ of mercury to the atmosphere (i.e., $81 \%$ of the total mercury originally contained in the fluids). Existing data on the atmospheric chemistry of mercury indicate that it is relatively stable. For example Lindberg, in a study of the mercury content of the plume from a coal-fired power plant, found no evidence of vapor-to-particle conversion at distances up to $22 \mathrm{~km}$ from the plant. ${ }^{72}$ Assuming no deposition or oxidation of mercury, the weighted average value of $x / Q$ over an $80 \mathrm{~km}$ radius around the facility is $8.7 \times 10^{-3} \mu \mathrm{g} \cdot \mathrm{s} / \mathrm{m}^{3} \cdot \mu \mathrm{g}$; the equivalent lifetime value is $3.7 \times 10^{-3} \mu \mathrm{g} \cdot \mathrm{s} / \mathrm{m}^{3} \cdot \mu \mathrm{g}$. An individual's lifetime risk $\mathrm{R}$ of manifesting muscle tremors resulting from the mercury emissions of the reference facility is $1.2 \times 10^{-6}$. The $\sigma_{g}$ for $R$ is 3.8 , and it is based on these values of $\sigma_{g}$ for the other parameters in the risk model: $\sigma_{g}(C)=1.7, \sigma_{g}(E)=1.5$, $\sigma_{g}(\chi / Q)=2.5$, and $\sigma_{g}(P)=2$. 
Health risks of $3000 \mathrm{MW}(\mathrm{e})$ in the Imperial Valley. To predict increases in ambient concentrations of mercury from $3000 \mathrm{MW}$ of development in the valley, we used the following mercury emission rates for $100-\mathrm{MW}$ e power plants located in these four resource areas: Salton Sea area, $1.6 \times 10^{-3} \mathrm{~g} / \mathrm{s}$; Brawley area, $3 \times 10^{-3} \mathrm{~g} / \mathrm{s}$; Heber area, $7.5 \times 10^{-3} \mathrm{~g} / \mathrm{s}$; and East Mesa area, $1.5 \times 10^{-2} \mathrm{~g} / \mathrm{s}$. The predicted concentrations of mercury in the valley ranged from a high of $96 \mathrm{ng} / \mathrm{m}^{3}$ to below $0.5 \mathrm{ng} / \mathrm{m}^{3}$. The equivalent lifetime concentrations corresponding to those predicted levels are 41 and $0.2 \mathrm{ng} / \mathrm{m}^{3}$, assuming that energy production lasts $30 \mathrm{y}$ and an average life expectancy of $70 \mathrm{y}$. The population risk for people living in the valley's cities and towns is calculated to be 7.6 cases of mercury-induced muscle tremors. The population risk we have calculated should be considered an upper-bound estimate for two reasons--first, we have neglected the effect of mercury clearance from the brain, and second, we have used a linear, no-threshold dose-response curve.

Cumulative Health Risks. For our analysis of the cumulative effects of mercury exposure, we assumed that the geometric mean of the geothermal fluids was $0.003 \mathrm{mg} / \mathrm{kg}$ of mercury and $81 \%$ of the mercury contained in the fluids processed for energy production was released to the atmosphere. For $21,000 \mathrm{MW}$ of development, the mean number of cases of mercury-induced tremors is calculated to be 55, while at the 95 th cumulative percentile 164 cases are expected.

\section{Effects of Radon}

Considerable attention has been devoted to deriving risk factors for the induction of lung cancer from exposure to radon and its short-lived daughters. This is because of the documented excess incidence of lung cancer among miners exposed to high levels of radon and its daughters underground. Several such studies have been reviewed recently in the BEIR-III report. ${ }^{73}$ They conclude that the risk estimates "now range from about 6 to 47 cases per $10^{6}$ PY per WLM." They further conclude,

The most likely risk estimates, at exposure of about $1 \mathrm{WL}$ and with characteristic smoking experience, are about 10 cases per $10^{6} \mathrm{PY}$ per WLM for the age group $35-49,20$ cases per $10^{6}$ PY per WLM for the age group $50-65$, and about 50 cases per $10^{6}$ PY per WLM for those over 65. These values apply to the age at diagnosis and are consistent with available followup data. ${ }^{73}$ 
In the quotes above, $P Y$ is the person-years at risk and is generally calculated by assuming a latent period of $10 \mathrm{y}$ and risk then lasting for life. ${ }^{73,74}$ The unit of exposure is the working level (WL) and is equal to $100 \mathrm{pCi} /$ liter of ${ }^{222} \mathrm{Rn}$ in equilibrium with its daughters. The unit of integrated exposure is working level month (WLM), where month is equal to $170 \mathrm{~h}$ (of occupational exposure).

These risk estimates are based on a linear dose-effect relationship and have been criticized as being at least an order of magnitude too high. ${ }^{75}$ If we accept them at face value, assume a log-normal distribution of risks, and assume that 6 and 47 cases per $10^{6}$ PY per WLM are at the $5 \%$ and $95 \%$ probability levels, then $\mu_{\mathrm{g}}=20 \times 10^{-6}$ and $\sigma_{\mathrm{g}}=2$.

Cohen has applied the age-specific risk factors to the U.S. population and has calculated that 21,765 cases of lung cancer per year are predicted based on a calculated exposure to background levels of radon of 0.22 WLM/year. ${ }^{74}$ From this we can derive an age- and sex-averaged absolute risk factor of $1 \times 10^{-3}$ per WLM. Cohen also notes that compared on an equivalent basis, the UNSCEAR derived value ${ }^{76}$ is about three times lower. ${ }^{77}$ We have therefore somewhat arbitrarily chosen to use a risk factor of $5 \times 10^{-4}$ per WLM and further assume that the range is from 0 to $1 \times 10^{-3}$ per WLM.

We then proceed with the calculation of $\mathrm{P}$ as follows :

$$
\begin{aligned}
& \mathrm{P}=\frac{\mathrm{m}^{3}}{10^{3} 1 \mathrm{iter}} \cdot \frac{1 \mathrm{iter} W \mathrm{~L}}{100 \mathrm{pCi}} \cdot 30 \mathrm{y} \cdot \frac{24 \mathrm{~h}}{\mathrm{~d}} \cdot \frac{365 \mathrm{~d}}{\mathrm{y}} \cdot \frac{\mathrm{M}}{170 \mathrm{~h}} \cdot \frac{5 \times 10^{-4}}{W M}, \\
& P=8 \times 10^{-6} \mathrm{~m}^{3} / \mathrm{PCi} .
\end{aligned}
$$

Health Risks of a Single Facility. The reference $100-\mathrm{MW}$ facility emits $9.76 \times 10^{5} \mathrm{pCi} / \mathrm{s}$ of ${ }^{222} \mathrm{Rn}$. That emission rate results in sector-averaged concentrations of ${ }^{222} \mathrm{Rn}$ ranging from $0.08 \mathrm{pCi} / \mathrm{m}^{3}$ at $10 \mathrm{~km}$ to $0.003 \mathrm{pCi} / \mathrm{m}^{3}$ at $80 \mathrm{~km}$. An individual's risk of lung cancer $R$ from $30 \mathrm{y}$ of exposure to those levels is $6.4 \times 10^{-7}$ and $2.4 \times 10^{-8}$ for 10 and $80 \mathrm{~km}$ respectively, with $\mathrm{P}$ equal to $8 \times 10^{-6} \mathrm{~m}^{3} / \mathrm{pCi}$. For $\mathrm{P}$ equal to $1.6 \times 10^{-5} \mathrm{~m}^{3} / \mathrm{pCi}$ (i.e., the basic risk factor is $1 \times 10^{-3} /$ WLM) the corresponding values of lung cancer risk at the two distances are $1.3 \times 10^{-6}$ and $4.8 \times 10^{-8}$.

Health Risks of $3000 \mathrm{MW}(\mathrm{e})$ in the Imperial Valley. Ambient concentrations of ${ }^{222} \mathrm{Rn}$ in the valley were calculated with the multiple-source Gaussian dispersion model using the following emission rates for $100-\mathrm{MW}$ e power plants in the four geothermal resource areas: Salton Sea area, $9 \times 10^{5} \mathrm{pCi} / \mathrm{s}$; Brawley area, $6 \times 10^{5} \mathrm{pCi} / \mathrm{s}$; Heber area, $1.6 \times 10^{6} \mathrm{pCi} / \mathrm{s}$; and East Mesa $1.5 \times 10^{6} \mathrm{pCi} / \mathrm{s}$. The total population exposure to ${ }^{222} \mathrm{Rn}$ among urban residents of the valley was calculated to be $5.7 \times 10^{4} \mathrm{pCi} \cdot$ persons $/ \mathrm{m}^{3}$. With $\mathrm{P}$ equal to $8 \times 10^{-6} \mathrm{~m}^{3} / \mathrm{pCi}$, we would expect about 0.5 lung cancers from $30 \mathrm{y}$ of exposure. 
Cumulative Health Risks. In our analysis of the cumulative health risks of ${ }^{222} \mathrm{Rn}$ emissions, we assumed that all geothermal fluids contain $508 \mathrm{pCi} /$ liter of ${ }^{222} \mathrm{Rn}$, the geometric mean concentration of 118 samples of geothermal waters analyzed by O'Connell and Kaufman. ${ }^{33}$ The mean value of the FPD for variable $R$, representing the cases of lung cancer over $30 \mathrm{y}$, is 8.5 , and at the 95 th cumulative percentile 26 cases are expected.

\section{Arsenicalism}

Although the inhalation of toxic gases is the primary source of public health risks, the chronic ingestion of groundwater or surface water contaminated with arsenic derived from geothermal fluids could also cause negative health effects, including skin cancer. Normally, residual geothermal fluids will be injected back into a geothermal reservoir for disposal, thus isolating the spent fluids from drinking water supplies. Nevertheless, if an injection well is improperly constructed, it is conceivable that injected fluids could escape to an aquifer containing potable water. Accidental spills to surface waters are also possible.

To determine the upper-bound level of individual risk for potential arsenic contamination, we chose to assess the risks of directly discharging fluids to surface waters. The case we chose for analysis is the operation of the Wairakei geothermal power plant in New Zealand, which is undoubtedly the worst example of how drinking water can be contaminated by fluid disposal. Since 1964 that plant has discharged all of its waste geothermal fluids into the Waikato River, the source of drinking water for a local town. Axtmann calculated an increase of $39 \mu \mathrm{g} / \mathrm{liter}$ in the arsenic concentration of the river under average flow conditions because of the geothermal discharges. ${ }^{78}$ Under low flow conditions, the incremental concentration could be as high as $250 \mu \mathrm{g} / \mathrm{liter}$. We have calculated the arsenic concentration in the spent geothermal fluids from Wairakei and compared it with concentrations of total arsenic from other resources in Table 8.

We estimate the incremental risk of developing skin cancer through the use of the simple model of the U.S. EPA ${ }^{81}$;

$R^{\prime}=C^{\prime} \cdot P^{\prime}$,

where

$R^{\prime}=$ an individual's lifetime risk of developing skin cancer from drinking water containing arsenic,

$C^{\prime}=$ concentration of arsenic in drinking water in $\mu \mathrm{g} /$ liter, and

$\mathrm{P}^{\prime}=$ lifetime probability of incurring cancer due to drinking water contaminated with arsenic in liter/ug. 
Table 8. Concentrations of total arsenic in geothermal fluids from ten geothermal resource areas.

Arsenic concentration

Geothermal resource area

(mg/liter)

Reference

Wairakei, New Zealand

2.7

78

Broadlands, New Zealand

3.3

19

A huachapan, El Salvador

11.3

19

Hatchobaru, Japan

3.2

19

Cerro Prieto, Mexico

$0.5-2.2$

29

Salton Sea, California

11

79

Brawley, California

2.6

79

Heber, California

0.1

79

East Mesa, California

0.2

79

The Geysers, California

$<0.004$

80

The value of $\mathrm{P}^{\prime}$ has been derived by the U.S. EPA and is $4 \times 10^{-4}$ per $\mu \mathrm{g} / \mathrm{liter} .^{81}$ This value is based entirely upon epidemiological studies of Taiwanese exposed to high concentrations of arsenic in drinking water from artesian wells. ${ }^{82,83}$ There is information that indicates that trivalent arsenic was the predominant form of arsenic present in the groundwater, 81 instead of the less toxic pentavalent form that is usually encountered in natural waters. ${ }^{84}$ The Wairakei geothermal fluids could also contain a significant amount of arsenic in the trivalent state because anaerobic conditions in the geothermal reservoir would probably limit its oxidation to the pentavalent form. Data supporting this assumption are from a study conducted by Crecelius et al. of arsenic speciation in the geothermal fluid from a well supporting the Cerro Prieto power plant in Mexico. 29 They found that the arsenic in the geothermal fluid prior to atmospheric exposure was $78 \%$ trivalent arsenic and $22 \%$ pentavalent arsenic. Additional information that corroborates the presence of trivalent arsenic in the Wairakei geothermal fluids is from Coulter who reports that trivalent arsenic represents as much as $70 \%$ of total arsenic in sediments in a lake fed by the contaminated Waikato River. ${ }^{85}$ Assuming that the speciation of arsenic in the Waikato River is similar to that of the arsenic in the drinking water consumed by the Taiwanese and that there are no significant genetic or dietary differences between the populations at risk, the incremental cancer risk of 
chronic ingestion of geothermal arsenic dissolved in the Waikato River would be about $1.6 \times 10^{-2}$. We estimate values of $\sigma_{g}$ to be 2.4 and 2 for $C^{\prime}$ and $\mathrm{P}^{\prime}$, respectively; and therefore 3 for $R^{\prime}$.

This calculated risk is surprisingly high, and we suggest that it should be viewed with caution. As mentioned above, the value for $\mathrm{P}^{\prime}$ was taken from the U.S. EPA, ${ }^{81}$ and is based on a linear, no-threshold, dose-response model. This, in fact, is almost certainly not the case since arsenic has been shown to be an essential element. ${ }^{86,87}$ And because it is essential, the dose-response relationship exhibits the U-shaped curve shown in Fig. 12. At low intake levels homeostasis exists, but as arsenic intake decreases to some as yet unspecified level, negative effects related to deficiency are manifested. ${ }^{88}$ The linear threshold or no-threshold model, in contrast, erroneously predicts toxic effects at the intake levels that are required for homeostasis. Moreover, at even lower intake levels, the linear no-threshold model predicts increasingly smaller probabilities of skin cancer, when in reality the probabilities of other harmful effects are increasing.

Other studies indicate that mammals have a detoxification mechanism of methylation $^{81}$ and that vitamin $C$ can counteract the toxic effects of arsenic ingestion. 90 Further, Valentine et al. report that "arsenic levels in water at concentrations of $100 \mu \mathrm{g} /$ liter or less seem not to produce an undue body burden." 91 Thus, we conclude that a threshold probably does exist for the production of skin cancer and $39 \mu \mathrm{g} /$ liter may be below the threshold level.

\section{OCCUPATIONAL HEALTH}

The geothermal industry in this country is relatively immature and has developed a significant start only at The Geysers vapor-dominated resource. Even here, the design of a typical power plant has only begun to stabilize after going through progressively major changes to accomplish abatement of hydrogen sulfide emissions. Because of the evolving nature of the industry, industrial hygiene problems have arisen as a result of initial design or changes and have then been reduced as problems were recognized and brought under control. A good example of this was a dramatic rise in occupational health problems when hydrogen sulfide abatement was first tried on a large scale with a retrofitted system. 92 This problem has since been brought under control with additional occupational hygiene efforts and newer designs of control technology equipment. As a result of these perturbations and of the small size of the industry, however, there are no occupational health statistics that can be applied directly to a full-scale industry. 


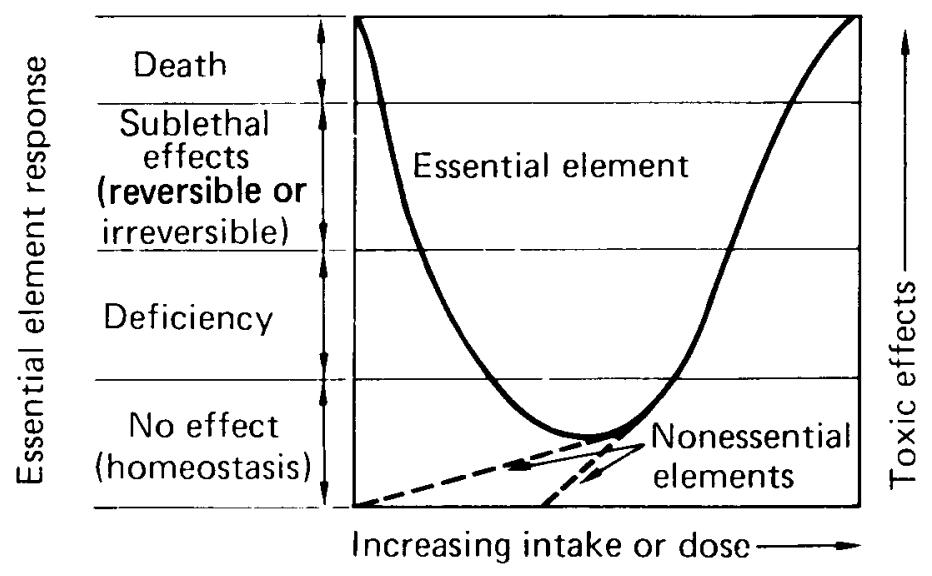

FIGURE 12. Dose-response curves for essential and nonessential elements. 88,89

The geothermal industry must deal with a wide variety of potential occupational hazards. The nature of these hazards has been described in detail by Hahn ${ }^{92,93}$ and also summarized by Zerwas et al. ${ }^{94}$ Briefly, the industry can be visualized as going through the following stages.

1. Exploration of the resource.

2. Well drilling and testing.

3. Power plant construction.

4. Power plant operation and maintenance (may include retrofitted control technology devices).

5. Power plant and field decommissioning.

The stages of most concern from an occupational health standpoint are 2 and 4 . The geothermal industry is somewhat unique in that it must deal with very large volumes of fluids that are very hot and under pressure, but these fluids are externally generated. If something goes wrong, these may be very difficult to stop. The fluids also contain contaminants that are abrasive and corrosive to the system itself and contain dissolved gases that are very toxic. If steam supplies must be vented, very high levels of noise can occur as well. The chemicals used in some hydrogen sulfide abatement schemes are themselves very toxic. Examples are sodium hydroxide and hydrogen peroxide and even recycled steel pickle acid that contains ferrous sulfate, which is useful as a catalyst. ${ }^{95}$

In general, the greatest hazard in the geothermal industry has been hydrogen sulfide. This gas is very toxic and has created problems particularly during the well 
drilling and power plant operation phases. ${ }^{93}$ Several individuals have been rendered unconscious. As a result of these problems, many changes in procedures, designs, and monitoring systems have evolved. In this regard, the geothermal industry is not unique. Hydrogen sulfide is a major problem in the oil and gas industry, ${ }^{42,43}$ was a major problem in the Swedish shale-oil industry, ${ }^{96}$ and is a significant problem even in the nuclear industry where it is used to make heavy water. 97

To assess the total risks from the operation of $21,000 \mathrm{MW}$ for $30 \mathrm{y}$, we first estimate the required man-years of effort. According to Zerwas et al., it takes 50 man-months to drill a geothermal well. ${ }^{94}$ Based on a resource temperature of about $230^{\circ} \mathrm{C}, 40$ production wells would be required to supply a $100-\mathrm{MW}$ e plant at one time, and we estimate that another 40 wells would be required over the $30-y$ plant life as replacements.

From experience at The Geysers, it takes about 1300 man-months to build a $110-\mathrm{MW}_{\mathrm{e}}$ power plant. Because water-dominated resource plants will be more complex, we estimate that 2000 man-months would be required. For decommissioning, we assume that another 500 man-months would be required, but there has not been any actual decommissioning experience.

For flashed-steam plants, we estimate that one worker is required per $M W_{e} \cdot y$ based on data from Wairakei and estimates from Baca. 98

Using the above numbers, we have calculated the total man-years to produce $21,000 \mathrm{MW}$ for $30 \mathrm{y}$, or $20 \times 10^{18} \mathrm{~J}$ of electrical energy. The results are shown in Table 9. Of the total, $85 \%$ of the predicted manpower is needed for the operation of the power plants. To predict deaths from occupational accidents, we have used the National Safety Council rates for 1977 as given by Cohen. ${ }^{99}$ For construction and decommissioning, we used the rate for construction workers of 60.3 per $10^{5}$ man-years; for drilling, we used the rate for mining and quarrying of 65.7 per $10^{5}$ man-years; and for operation, we used the rate for transportation and public utilities of 32.7 per $10^{5}$ man-years. These results are also shown in Table 9.

To calculate the number of occupational diseases, we have used California statistics for 1974 . $^{100}$ For construction the rate is 5.3 per $10^{3}$ man-years. For drilling, we used the rate for mineral extraction of 3.3 per $10^{3}$ man-years. Because of the unique problems at geothermal power plants, we have chosen not to use the rate of 6.2 per $10^{3}$ man-years for private utilities, but have used instead the rate of 10.1 per $10^{3}$ man-years for production workers in the manufacture of petroleum products. This choice is somewhat arbitrary but is based on the concept that both classes of workers are at similar risk of exposure to hydrogen sulfide and somewhat similar industrial conditions. These results are also shown in Table 9. 
Table 9. Estimated man-years of labor and numbers of accidental deaths and occupational diseases for the production of $21,000 \mathrm{MW}$ for $30 \mathrm{y}$. All numbers have been rounded.

\begin{tabular}{lccc}
\hline Segment & $\begin{array}{c}\text { Man-years } \\
\text { of labor }\end{array}$ & $\begin{array}{c}\text { Accidental } \\
\text { deaths }\end{array}$ & $\begin{array}{c}\text { Occupational } \\
\text { diseases }\end{array}$ \\
\hline Drilling & $70 \times 10^{3}$ & 46 & 230 \\
Construction & $32 \times 10^{3}$ & 19 & 170 \\
Operation & $630 \times 10^{3}$ & 210 & 6400 \\
Decommissioning & $8 \times 10^{3}$ & $\frac{5}{280}$ & $\frac{42}{6800}$ \\
\multicolumn{1}{c}{ TOTAL } & $\frac{740 \times 10^{3}}{\text { Normalized to } 10^{18} \mathrm{~J} \text { of electrical energy production }}$ \\
\multicolumn{1}{c}{ TOTAL } & $37 \times 10^{3}$ & 14 & 340 \\
\hline
\end{tabular}

Finally, to facilitate comparison with other industries, we have normalized the predicted number of man-years, accidental deaths, and occupational diseases to the production of $10^{18} \mathrm{~J}$ (see Table 9 ).

\section{ECOSYSTEM EFFECTS}

Three potential sources of ecological effects related to the operation of geothermal power plants are releases of noncondensing gases, accidental spills of geothermal fluids, and cooling tower emissions of drift containing toxic substances. Releases of noncondensing gases are only a problem with flashed-steam power plants since binary-fluid plants should not have gaseous emissions so long as geothermal fluids remain pressurized. Of all the noncondensing gases, hydrogen sulfide and carbon dioxide are the only ones that are expected to affect natural vegetation and crops in the vicinity of power plants. Because of the large quantities of geothermal fluids that must be extracted, processed, and disposed of, another potential source of ecological effects is the accidental release of geothermal fluids. Although the effects of a spill would be local in nature, the cumulative effects at the reference level of power production (i.e., $21,000 \mathrm{MW}_{\mathrm{e}}$ ) may be important. Drift from cooling towers is the other concern. At The 
Geysers, boron contained in drift is probably the cause of foliar damage to native trees near some of the power plants. ${ }^{101}$ Boron emissions from cooling towers at geothermal plants located elsewhere could also produce phytotoxic effects. For example in the Imperial Valley where power plants will be adjacent to crop lands, boron emissions could cause crop damage. In this section, however, we will restrict our analyses to the potential effects of noncondensing gases and accidental spills, leaving the subject of cooling tower emissions for a detailed analysis in the second-year HEED on geothermal energy.

\section{EMISSIONS OF HYDROGEN SULFIDE AND CARBON DIOXIDE}

Most of the recent work on the phytotoxicity of hydrogen sulfide has been conducted by Thompson and Kats ${ }^{102}$ and Thompson et al. ${ }^{103}$ For the experiments described in the first paper they subjected alfalfa, Thompson seedless grapes, lettuce, sugar beets, California buckeye, ponderosa pine, and Douglas fir to continuous fumigations of $30 \mathrm{ppbv}$ $\left(42 \mu \mathrm{g} / \mathrm{m}^{3}\right), 300 \mathrm{ppbv}\left(420 \mu \mathrm{g} / \mathrm{m}^{3}\right)$, and $3000 \mathrm{ppbv}\left(4200 \mu \mathrm{g} / \mathrm{m}^{3}\right)$ of hydrogen sulfide. At the 300-ppbv and 3000-ppbv treatments, most of the plants exhibited stress (i.e., foliar damage or suppressed yield) when compared with the control plants. At 30 ppbv the forest plants did not show any noticeable effects. However, the growth of alfalfa, grapes, sugar beets, and lettuce was actually stimulated at the lower exposure level. In the second paper they reported the results of treating plants with 50-ppmv carbon dioxide and 300-ppbv hydrogen sulfide. Interestingly enough, they found that the addition of 50-ppmv carbon dioxide generally counteracted the negative effects of hydrogen sulfide alone at the 300-ppbv exposure level, and in the cases of cotton and alfalfa, the treatments of hydrogen sulfide plus carbon dioxide actually caused more growth in the fumigated plants than in the controls.

Ambient concentrations of hydrogen sulfide in the vicinity of a reference, $100-\mathrm{MW}_{\mathrm{e}}$ flashed-steam geothermal facility processing fluids containing $5.4 \mathrm{mg} / \mathrm{kg}$ of hydrogen sulfide would range from about $2 \mu \mathrm{g} / \mathrm{m}^{3}$ at a distance of $5 \mathrm{~km}$ to $0.7 \mu \mathrm{g} / \mathrm{m}^{3}$ at $10 \mathrm{~km}$, assuming no emission controls. If the fluids contained ten times as much hydrogen sulfide, the concentration range would be 7 to $19 \mu \mathrm{g} / \mathrm{m}^{3}$. So even without abatement of hydrogen sulfide, ambient levels are not expected to have deleterious effects on plants, and in fact, the low concentrations may have a minor fertilizing effect.

The potential phytotoxic effects of hydrogen sulfide and carbon dioxide emissions from $3000 \mathrm{MW}_{\mathrm{e}}$ of geothermal development in the Imperial Valley have been analyzed by Kercher. ${ }^{104}$ In his study, he used a computer model to simulate the growth of sugar beets, an important cash-crop in the valley, exposed to ambient concentrations of 
hydrogen sulfide as well as carbon dioxide emitted from geothermal facilities. Results of that analysis were then used to assess the possible effects on other crops. Without hydrogen sulfide controls and with no emissions of carbon dioxide, the model predicts that the growth of sugar beets would be enhanced throughout the valley, with beets at some places displaying increases of $10 \%$ over the control case. Emissions of hydrogen sulfide from all power plants would have to be over $100 \mathrm{t} / \mathrm{d}$ before the growth of sugar beets would be reduced. 104 Unabated emissions from all power plants making up the $3000-\mathrm{MW}$ scenario, by comparison, are $40 \mathrm{t} / \mathrm{d}$. When carbon dioxide emissions were included in the model simulations along with the hydrogen sulfide emissions, only increased yields were predicted. The results of the sugar beet simulations were then used to estimate the effects on other crops by using comparative data on the sensitivities of sugar beets and other crops to hydrogen sulfide. In this regard, lettuce and alfalfa are 1.6 and 3.4 times more susceptible to hydrogen sulfide phytotoxicity, and consequently, emission rates of approximately 70 and $30 \mathrm{t} / \mathrm{d}$ from all power plants would result in potential injury. However, the compensating influence of carbon dixoide would probably mitigate those effects.

In conclusion, emissions of both hydrogen sulfide and carbon dioxide from geothermal facilities in the reference industry will not result in negative effects on crops and native vegetation. Indeed, growth enhancement is more likely than retardation. Even smaller effects (no significant enhancement) will occur if hydrogen sulfide is abated.

\section{ACCIDENTAL SPILLS}

Geothermal power plants must rely on large quantities of geothermal fluids to produce electricity. A $100-\mathrm{MW}$ e facility, for example, would process between $3.5 \times 10^{3}$ to $1.85 \times 10^{4} \mathrm{~m}^{3} / \mathrm{h}$ of fluids, based on requirements of $35 \mathrm{~m}^{3} / \mathrm{MW} / \cdot \mathrm{h}\left(275^{\circ} \mathrm{C}\right.$ resource temperature) and $185 \mathrm{~m}^{3} / \mathrm{MW}, \cdot \mathrm{h}\left(150^{\circ} \mathrm{C}\right.$ resource temperature). A potential danger during the extraction, transportation, processing, and disposal of geothermal fluids is the inadvertent release of those hot fluids to adjacent lands. Such a spill would damage vegetation on the affected lands and contaminate soils. To assess the risks of accidental releases, we must determine how much land area would be covered by fluids after a spill occurs and we must also estimate the probability of events that result in spills.

The surface area affected by spills per $M W_{e} \cdot y$ of energy production is calculated from

$A=\frac{F \cdot T \cdot S}{D}$, 
where

$A=$ area affected by a spill in $\mathrm{m}^{2} / \mathrm{MW}_{\mathrm{e}_{3}} \cdot \mathrm{y}$,

$F=$ flowrate of geothermal fluids in $\mathrm{m}^{3} / \mathrm{h}$,

$\mathrm{T}=$ duration of spill in $\mathrm{h}$,

$\mathrm{D}=$ depth of spill in $\mathrm{m}$, and

$\mathrm{S}=$ probability of a release per unit of energy production in fraction/MW $\mathrm{e}^{\bullet} \mathrm{y} \cdot$

The critical parameter in this analysis is the probability of a release per unit of energy production S. It is quite difficult to accurately quantify the probability of a spill event without data on the frequency of spills at actual geothermal power plants. Nevertheless, release probabilities can be estimated with failure-rate data on individual components (e.g., valves, pumps, piping, etc.) in a power plant. Sung et al. have used such data to estimate the probabilities of two types of geothermal fluid releases: (1) critical, which they define as "a single-point rupture that can be controlled only by closing the wellhead valves" and (2) major, which they define as "a single-point rupture that is controllable by valves other than the wellhead valves." 105 They estimate a probability of $3.7 \times 10^{-5}$ for a critical release during the 40-y design life of a 50-MW flashed-steam

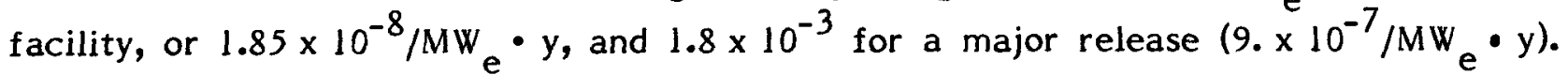
The reference plant is assumed to have dual pipes carrying fluids from a wellfield to central steam separators, and hence half of the total flow from a wellfield would be released if a critical failure occurs. Major releases, though, would be considerably smaller because of the availability of more valves to control the release.

To analyze the amount of land affected by both critical and major releases, we used the MACROI code to combine the parameter distributions shown in Table 10. The maximum value of $\mathrm{F}$ in a critical release is assumed to be half of the flow of a $50-\mathrm{MW}$ power plant requiring $100 \mathrm{~m}^{3} / \mathrm{MW}_{\mathrm{e}} \cdot \mathrm{h}$ of geothermal fluids, our maximum estimate of flow for a reference geothermal facility. The minimum flow associated with a critical release was arbitrarily assumed to be a tenth of the maximum flow. The maximum flow during a major release was set equal to the minimum discharge during a critical release. The median values of $A$ for critical and major releases were calculated to be $1.6 \times 10^{-4}$ and $8.2 \times 10^{-4} \mathrm{~m}^{2} / \mathrm{MW} \mathrm{e}^{-\mathrm{y}}$. At the reference level of geothermal energy production (i.e.,

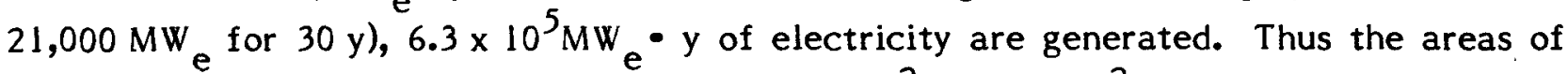
land affected for the reference industry are $101 \mathrm{~m}^{2}$ and $517 \mathrm{~m}^{2}$, for a total of just over $600 \mathrm{~m}^{2}$. At the 99th percentile of the cumulative distributions for A, a total of $5 \times 10^{4} \mathrm{~m}^{2}$ ( $5 \mathrm{ha}$ ) would be affected by both types of spills. 
Table 10. Parameter distributions and values used in the analysis of the consequences of accidental releases of geothermal fluids.

\begin{tabular}{ccccc}
\hline & & & \multicolumn{2}{c}{ Distribution values } \\
\cline { 4 - 5 } Parameter & Units & Distribution & Critical release & Major release \\
F & $\mathrm{m}^{3} / \mathrm{h}$ & Triangle & $\frac{(\text { minimum } / \text { maximum })^{\mathrm{a}}}{250 / 2500}$ & $\frac{(\text { minimum } / \text { maximum })^{\mathrm{a}}}{25 / 250}$ \\
$\mathrm{~T}$ & $\mathrm{~h}$ & Triangle & $0.166 / 1$ & $0.166 / 1$ \\
$\mathrm{D}$ & $\mathrm{m}$ & Uniform & $0.013 / 0.152$ & $0.013 / 0.152$ \\
$\mathrm{~S}$ & fraction $/ \mathrm{MW}$ & & $\left(\mu_{\mathrm{g}} / \sigma_{\mathrm{g}}\right)$ & $\frac{\left(\mu_{\mathrm{g}} / \sigma_{\mathrm{g}}\right)}{9 \times 10^{-7} / 5}$ \\
\hline
\end{tabular}

a The minimum and maximum values of the triangle and uniform distributions used to calculate the median values.

If we assume that 12 ha of land are required for a typical $100-\mathrm{MW}$ e geothermal power plant, $2.5 \times 10^{3}$ ha of land would be required for facilities making up the reference industry. So in a comparative sense, the potential effect of spills on habitats adjacent to geothermal facilities is minor compared with the disruption of habitats caused by land requirements of power plants and well fields (additional site-specific impacts on habitats will of course be caused by roads, transmission line corridors, etc.).

Accidental releases of fluids can be contained by earthen berms and sumps. In addition, pressure-activated sensors can be used to detect inadvertent spills so that remedial action can be taken. Preventive maintenance of equipment will further reduce the likelihood of large spills. To improve the probabilistic analysis of spills, the value of $S$ needs to be improved. Sung et al. ${ }^{105}$ based their estimates of $S$ on failure rate data for equipment in other industries and for power plant designs that may not prove to be representative. Moreover, the estimate of $S$ does not include human errors, and that deficiency could significantly change the results. Additional data on the frequency of spills and causes will have to be collected as the geothermal power industry expands in order to improve our estimates of the spill risk. Also, studies are needed to examine the potential for blowouts of geothermal wells. Such events could constitute a more significant threat to habitats. 
The analyses in this HEED provide some valuable insights into the manageability of health and environmental risks of geothermal power production, the relative importance of different effects, and the need for future research to reduce the uncertainties of the risk analyses. For most of the risks we studied, we compared the effects associated with both controlled and uncontrolled releases of effluents to determine the changes in health risks.

In our analysis of hydrogen sulfide, for example, we showed that emissions of that gas from geothermal facilities would probably have to be kept below $1 \mathrm{~g} / \mathrm{s}$ to avoid the occurrence of unwanted odors in the vicinity of power plants. We further estimated that nearly $60 \%$ of the resource areas would have at least one power plant with emissions greater than $1 \mathrm{~g} / \mathrm{s}$, assuming that no controls are implemented and that geothermal fluids contain $0.7 \mathrm{mg} / \mathrm{kg}$ of hydrogen sulfide.

The use of hydrogen sulfide abatement equipment to minimize potential odor problems has a second-order benefit--the reduction of health risks from exposure to particulate sulfate, the oxidation by-product of hydrogen sulfide in the atmosphere. The sulfate-related health risk of $21,000 \mathrm{MW}$ of energy production was estimated to be 23 premature deaths per year without control of emissions, compared with $0.3 / y$ when controls are used to limit emissions of hydrogen sulfide to $36 \mathrm{~g} / \mathrm{MW}$ to reduce odors. The chemical treatment of noncondensing gases to remove hydrogen sulfide may also lower emissions of mercury, benzene, and radon. However, the degree of control in that particular situation is not known at this time. Interestingly enough, efforts to abate hydrogen sulfide have led to a secondary health problem, occupational exposure to toxic substances used in the control systems (e.g., sodium hydroxide). Thus, the management of one health risk can actually lead to another unless precautions are taken.

The public health risks of geothermal development could be greatly reduced by implementing binary-fluid power plants, which are not expected to release noncondensing gases so long as geothermal fluids are pressurized. Again, the occupational risks of the newer, binary-fluid technologies could be greater than flashed-steam systems--this should be the subject of future research. One drawback of the binary-fluid plants is their need for external sources of cooling water. In the arid West, the siting of those facilities may be a real problem and consequently their use may be severly restricted.

The occupational health risks that we have estimated for the reference geothermal industry are significantly greater than the public health risks. We used occupational data from similar industries to calculate the occupational risks, and unfortunately there is no 
way of knowing the direction of bias caused by using the surrogate data until more data become available on operating geothermal facilities. Furthermore, until more is known about the sources of occupational illnesses and deaths, it is not possible to determine how effective industrial hygiene practices will be in reducing risks.

During our analyses of the health and environmental risks of producing geothermal energy, several avenues of future research became apparent that should help to reduce some uncertainties of risk estimates.

- In general, more data are needed on the chemistry of geothermal fluids. A program of sampling and analyses of fluids from more geothermal resources would be a cost-effective way of reducing an important source of uncertainty in our analyses. This is especially true for benzene, an organic gas that has only recently been discovered in noncondensing gases. Additional data on hydrogen sulfide and mercury would also be helpful.

- The analyses of the health risks of the noncondensing gases were based on the assumption that the predicted outdoor levels of the gases were the same as the indoor levels. We know that this is not true for all gases, and studies should be implemented to investigate the indoor and outdoor relationships for all of the noncondensing gases.

- A major source of uncertainty involves the dose-response relationships of the substances we have assessed. It is clear that more laboratory and epidemiological studies are needed to increase our understanding of the toxicology of the different gases. Additional information would be particularly helpful on the dose-response function for sulfate aerosols. Our analysis of the health risk of mercury would be improved if we knew more about the clearance rate of mercury from the brain. More research is needed on the homeostatic function of arsenic.

- Data should be collected on the frequency of accidental releases of geothermal fluids and their potential sources. These data are needed to verify the risk estimates we have made using failure-rate data of equipment common to other industries. 


\section{ACKNOWLEDGMENTS}

We thank N. Nehring and D. Des Marais who supplied us with useful information on the occurrence of benzene in geothermal fluids. We would also like to acknowledge the help received from $Y$. Ricker and A. Fountain during the final preparation of the document. 


\section{REFERENCES}

1. L. J. P. Muffler, Ed., Assessment of Geothermal Resources of the United States--1978, U.S. Geological Survey, Arlington, VA, Circular 790 (1979).

2. L. Rybach, "Geothermal Systems, Conductive Heat Flow, Geothermal Anomalies," in Geothermal Systems: Principles and Case Histories, L. Rybach and L.J.P. Muffler, Eds. (John Wiley and Sons, Ltd., New York, 1981), p. 3.

3. D. W. Layton and L. R. Anspaugh, Health Impacts of Geothermal Energy, International Symposium on Health Impacts of Different Sources of Energy, Nashville, TN, June 22-26, 1981.

4. G. Heiken, H. Murphy, G. Nunz, R. Potter, and C. Grigsby, "Hot Dry Rock Geothermal Energy," Amer. Sci. 69, 400 (1981).

5. L. R. Anspaugh and J. L. Hahn, "Human Health Implications of Geothermal Energy," in Health Implications of New Energy Technologies, W.N. Rom and V.E. Archer, Eds. (Ann Arbor Science Publishers, Inc., Ann Arbor, MI, 1980), p. 565.

6. D. L. Ermak and P. L. Phelps, An Environmental Overview of Geothermal Development: The Geysers-Calistoga KGRA, Volume 1. Issues and Recommendations, Lawrence Livermore Laboratory, Livermore, CA, UCRL-52496, vol. 1 (1978).

7. D. W. Layton and W. F. Morris, "Geothermal Power: Accidental Fluid Releases and Waste Disposal," Chem. Eng. Prog. 77(4), 62 (1981).

8. D. W. Layton, An Assessment of Geothermal Development in the Imperial Valley of California; Environment, Health, Socioeconomics, and Environmental Control Technology, Executive Summary, U.S. Department of Energy, Washington, DC, DOE/TIC-11308 (1980).

9. J. H. Anderson, "The Vapor-Turbine Cycle for Geothermal Power Generation," in Geothermal Energy: Resources, Production, Stimulation, P. Kruger and C. Otte, Eds. (Stanford University Press, Stanford, CA, (1973), p. 163. 
10. W. L. Pope, P. A. Doyle, H. S. Pines, R. L. Fulton, L. F. Silvester, and J. M. Angevine, "Conceptual Design Optimization," in Sourcebook on the Production of Electricity from Geothermal Energy, J. Kestin, R. DiPippo, H.E. Khalifa, and D.J. Ryley, Eds. (Brown University, Providence, RI, 1980), p. 729.

11. C. A. Brook, "Variability and Sources of Hydrogen Sulfide and Other Gases in Steam at The Geysers," in Research in The Geysers-Clear Lake Geothermal Area, Northern California, R. J. McLaughlin and J. M. Donnelly-Nolon, Eds., U.S. Geological Survey, Washington DC, Professional Paper 1141 (1981), p. 193.

12. E. F. Wahl, Geothermal Energy Utilization (John Wiley and Sons, New York, 1977).

13. D. L. Ermak, R. A. Nyholm, and P. H. Gudiksen, Imperial Valley Environmental Project: Air Quality Assessment, Lawrence Livermore Laboratory, Livermore, CA, UCRL-52699 (1979).

14. F. B. Stephens, J. H. Hill, and P. L. Phelps, Jr., State-of-the-Art Hydrogen Sulfide Control for Geothermal Energy Systems: 1979, U.S. Department of Energy, Washington, DC, DOE/EV-0068 (1980).

15. K. L. White, A. C. Hill, and W. O. Ursenbach, Environmental Overview Report on Utah Geothermal Resource Areas, University of Utah Research Institute, Salt Lake City, UT, UCRL-13955, vols. 1 and 2 (1978).

16. P. F. Ellis and M. F. Conover, Materials Selection Guidelines for Geothermal Energy Utilization Systems, U.S. Department of Energy, Washington, DC, DOE/RA/27026-1 (1981).

17. S. R. Cosner and J. A. Apps, A Compilation of Data on Fluids from Geothermal Resources in the United States, Lawrence Berkeley Laboratory, Berkeley, CA, LBL-5936 (1978).

18. R. C. Axtmann, "Emission Control of Gas Effluents from Geothermal Power Plants," Environ. Lett. 8 , 135 (1975).

19. R. DiPippo, Geothermal Energy as a Source of Electricity, U.S. Department of Energy, Washington, DC, DOE/RA/28320-1 (1980). 
20. Pacific Gas and Electric Co. (PG\&E), Notice of Intention, Geysers Unit 17, PG\&E, San Francisco, CA (1978).

21. N. L. Nehring and J. J. Fausto, "Gases in Steam from Cerro Prieto Geothermal Wells with a Discussion of Steam/Gas Ratio Measurements," Geotherm. ㅇ, 253 (1979).

22. D. W. Layton, D. J. Powers, P. Leitner, N. B. Crow, P. H. Gudiksen, and Y. E. Ricker, Environmental Summary Document for the Republic Geothermal, Inc., Application for a Geothermal Loan Guaranty Project; $64 \mathrm{MW}$ Well Field and $48 \mathrm{MW}$ (Net) Geothermal Power Plant, Lawrence Livermore Laboratory, Livermore, CA, UCID- 18095 (1979).

23. N. L. Nehring, "Gases from Springs and Wells in The Geysers-Clear Lake Area," in Research in The Geysers-Clear Lake Geothermal Area, Northern California, R. J. McLaughlin and J.M. Donnelly-Nolan, Eds., U.S. Geological Survey, Washington, DC, Professional Paper 114 I (1981), p. 205.

24. A. H. Truesdell and N. L. Nehring, "Gases and Water Isotopes in a Geochemical Section Across the Larderello, Italy, Geothermal Field," Pageoph 117, 276 (1978/79).

25. D. J. Des Marais, J. H. Donchin, N. L. Nehring, and A. H. Truesdell, "Molecular Carbon Isotopic Evidence for the Origin of Geothermal Hydrocarbons," Nature 292, $826(1981)$.

26. N. L. Nehring and A. H. Truesdell, "Hydrocarbon Gases in Some Volcanic and Geothermal Systems," Geotherm. Resour. Counc. Trans. 2, 483 (1978).

27. D. W. Robertson, E. A. Crecelius, J. S. Fruchter, and J. D. Ludwick, "Mercury Emissions from Geothermal Power Plants," Science 196, 1094 (1977).

28. D. W. Robertson, J. S. Fruchter, J. D. Ludwick, C. L. Wilkerson, E. A. Crecelius, and J. C. Evans, "Chemical Characterization of Gases and Volatile Heavy Metals in Geothermal Effluents," Geotherm. Resour. Counc. Trans. 2, 579 (1978).

29. E. A. Crecelius, D. E. Robertson, J. S. Fruchter, and J. D. Ludwick, "Chemical Forms of Mercury and Arsenic Emitted by a Geothermal Power Plant," in Trace Substances in Environmental Health--X, D. D. Hemphill, Ed. (University of Missouri, Columbia, MO, 1976), p. 287. 
30. H. L. Beck, "Gamma Radiation from Radon Daughters in the Atmosphere," J. Geophys. Res. 79, 2215 (1974).

31. L. R. Anspaugh, Final Report on the Investigation of the Impact of the Release of 222-Rn, its Daughters, and Precursors at The Geysers Geothermal Field and Surrounding Area, Lawrence Livermore Laboratory, Livermore, CA, Environmental Sciences Division Report (1978).

32. M. H. Wilkening, W. E. Clements, and D. Stanley, "Radon 222 Flux Measurements in Widely Separated Areas," in The Natural Radiation Environment II, J.A.S. Adams, W.M. Lowder, and T.F. Gesell, Eds. (NTIS, Springfield, VA, CONF-720805-P2, 1972), p. 717.

33. M. F. O'Connell and R. F. Kaufman, Radioactivity Associated with Geothermal Waters--the Western United States. Basic Data, U.S. Environmental Protection Agency, Office of Radiation Programs, Las Vegas, NV, ORP/LV-75-8A (1976).

34. L. R. Anspaugh and P. Leitner, "Health and Safety Concerns," in An Assessment of Geothermal Development in the Imperial Valley of California, Volume 1. Environment, Health, and Socioeconomics, D. W. Layton, Ed., U.S. Department of Energy, Washington, DC, DOE/EV-0092, vol. 1 (1980).

35. J. D. Spengler, "Comments," J. Air Pollut. Control Assoc. 29, 929 (1979).

36. D. J. Moschandreas, J. Zabransky, and D. J. Pelton, Comparison of Indoor and Outdoor Air Quality, Electric Power Research Institute, Palo Alto, CA, EPRI EA-1733 (1981).

37. E. Crouch and R. Wilson, "Regulation of Carcinogens," Risk Anal. 1, 47 (1981).

38. D. L. Shaeffer and F. O. Hoffman, "Uncertainties in Radiological Assessments--A Statistical Analysis of Radioiodine Transport via the Pasture-Cow-Milk Pathway," Nuclear Tech. 45 (1), 99 (1979).

39. M. G. Morgan, S. C. Morris, A.K. Meier, and D.L. Shenk, "A Probabilistic Methodology for Estimating Air Pollution Health Effects from Coal-Fired Power Plants," Energy Syst. Policy 2, 287 (1978). 
40. G. Schwarz and F. O. Hoffman, "Imprecision of Dose Predictions for Radionuclides Released to the Environment: An Application of a Monte Carlo Simulation Technique," Environ. Intern. 4, 289 (1980).

41. L. L. Edwards, MACRO1: A Code to Test a Methodology for Analyzing Nuclear-Waste Management Systems, Lawrence Livermore Laboratory, Livermore, CA, UCRL-52736 (1979).

42. U.S. National Research Council, Hydrogen Sulfide (University Park Press, Baltimore, MD, 1979).

43. U.S. National Institute for Occupational Safety and Health (NIOSH), Criteria for a Recommended Standard...Occupational Exposure to Hydrogen Sulfide, NIOSH, Washington, DC, 77-158 (1977).

44. D. L. Ermak, R. A. Nyholm, and P. H. Gudiksen, "Potential Air Quality Impacts of Large-Scale Geothermal Energy Development in the Imperial Valley," Atmos. Environ. 14, 1321 (1980).

45. W. F. Morris and F. B. Stephens, Strategies for Steam Handling and Hydrogen Sulfide Abatement at Geothermal Power Plants in The Geysers Area of Northern California, Lawrence Livermore National Laboratory, Livermore, CA, UCRL-53137 (1981).

46. B. G. Ferris, "Health Effeçts of Exposure to Low Levels of Regulated Air Pollutants. A Critical Review," J. Air Pollut. Control Assoc. 28, 482 (1978).

47. R. Mendelsohn and G. Orcutt, "An Empirical Analysis of Air Pollution Dose-Response Curves," J. Environ. Econ. Manage. 6, 85 (1979).

48. L. B. Lave and E. P. Seskin, Air Pollution and Public Health (The Johns Hopkins University Press, Baltimore, MD, 1977).

49. M. O. Amdur, "Toxicological Appraisal of Particulate Matter, Oxides of Sulfur, and Sulfuric Acid," J. Air Pollut. Control Assoc. 9, 638 (1969). 
50. R. Wilson, S. D. Colome, J. D. Spengler, and D. G. Wilson, Health Effects of Fossil Fuel Burning. Assessment and Mitigation (Ballinger Publishing Company, Cambridge, MA, 1980).

51. D. L. Ermak and R. A. Nyholm, Multiple Source Dispersion Model, Lawrence Livermore Laboratory, Livermore, CA, UCRL-52592 (1978).

52. J. L. Sprung, "Tropospheric Oxidation $\mathrm{H}_{2} \mathrm{~S}$," in Advances in Environmental Science and Technology (John Wiley and Sons, New York, 1977), p. 263.

53. L. Newman, "Atmospheric Oxidation of Sulfur Dioxide," in Atmospheric Sulfur Deposition. Environmental Impact and Health Effects (Ann Arbor Science Publishers, Inc., Ann Arbor, MI, 1979), p. 131.

54. H. S. Judeikis and A. G. Wren, "Deposition of $\mathrm{H}_{2} \mathrm{~S}$ and Dimethyl Sulfide on Selected Soil Materials," Atmos. Environ. 11, 1221 (1977).

55. J. N. de Wys, A. C. Hill, and E. Robinson, "Assessment of the Fate of Sulfur Dioxide from a Point Source," Atmos. Environ. 12, 633 (1978).

56. J. A. Garland, "Dry and Wet Removal of Sulfur from the Atmosphere," Atmos. Environ. 12, 349 (1978).

57. R. R. Draxler, "An Improved Gaussian Model for Long-Term Average Air Concentration Estimates," Atmos. Environ. 14, 597 (1980).

58. P. H. Gudiksen, D. L. Ermak, K. C. Lamson, M. C. Axelrod, and R. A. Nyholm, The Potential Air Quality Impact of Geothermal Power Production in the Imperial Valley, Lawrence Livermore Laboratory, Livermore, CA, UCRL-52797 (1979).

59. D. L. Ermak, Potential Growth of Electric Power Production from Imperial Valley Geothermal Resources, Lawrence Livermore Laboratory, Livermore, CA, UCRL-52252 (1977).

60. M. Aksoy, S. Erdem, and G. Dincol, "Leukemia in Shoe-Workers Exposed Chronically to Benzene," Blood 44, 837 (1974). 
61. P. F. Infante, J. K. Wagoner, R. A. Rinsky, and R. F. Young, "Leukaemia in Benzene Workers," Lancet 2, 76 (1977).

62. R. E. Albert, Carcinogen Assessment Group's Final Report on Population Risk to Ambient Benzene Exposure, U.S. Environmental Protection Agency, Research Triangle Park, NC, EPA-450/5-80-004 (1979).

63. J. V. Ordonez, J. A. Carillo, M. Miranda, and J. L. Gale, "Estudio Epidemiologico de una Enfermedad Considerada como Encefalitis en la Region de los Altos de Guatemala," Bol. Of. Sanit. Panam. 60, 18 (1966).

64. F. Bakir, S. F. Damluji, L. Amin-Zaki, M. Murtadha, A. Khalidi, N. Y. Al-Rawi, S. Tikriti, H. I. Dhahir, T. W. Clarkson, J. C. Smith, and R. A. Doherty, "Methylmercury Poisoning in Iraq," Science 181, 230 (1973).

65. H. B. Gerstner and J. E. Huff, "Clinical Toxicology of Mercury," J. Toxicol. Environ. Health 2, 491 (1977).

66. D. Benning, "Outbreak of Mercury Poisoning in Ohio," Ind. Med. Surg. 27, 354 (1958).

67. Y. M. El-Sadik and A-A. El-Dakhakhny, "Effects of Exposure of Workers to Mercury at a Sodium Hydroxide Producing Plant," Am. Ind. Hyg. Assoc. J. 31, 705 (1970).

68. B. Kesic and V. Haeusler, "Hematological Investigation of Workers Exposed to Mercury Vapors," Ind. Med. Surg. 20, 485 (1951).

69. R. G. Smith, A. J. Vorwald, L. S. Patil, and T. F. Mooney, "Effects of Exposure to Mercury in the Manufacture of Chlorine," Am. Ind. Hyg. Assoc. J. 31, 687 (1970).

70. R. C. Harriss and C. Hohenemser, "Mercury--Measuring and Managing the Risk," Environment 20(9), 25 (1978).

71. T. Suzuki, "Dose-Effect and Dose-Response Relationships of Mercury and its Derivatives," in The Biogeochemistry of Mercury in the Environment, J.O. Nriagu, Ed. (Elsevier-North Holland Biomedical Press, New York, 1979), P 399. 
72. S. E. Lindberg, "Mercury Partitioning in a Power Plant Plume and its Influence on Atmospheric Removal Mechanisms," Atmos. Environ. 14227 (1980).

73. E. P. Radford, Chairman, Committee on the Biological Effects of Ionizing Radiation, The Effects on Populations of Exposure to Low Levels of Ionizing Radiation: 1980 (National Academy Press, Washington, DC, 1980).

74. B. L. Cohen, "Health Effects of Radon from Insulation of Buildings," Health Phys. 39, 937 (1980).

75. A. F. Cohen and B. L. Cohen, "Tests of the Linearity Assumption in the Dose-Effect Relationship for Radiation-Induced Cancer," Health Phys. 38, 53 (1980).

76. United Nations Scientific Committee on the Effects of Atomic Radiation, Sources and Effects of Ionizing Radiation (United Nations, New York, 1977).

77. B. L. Cohen, "Proposals on Use of the BEIR-III Report in Environmental Assessments," Health Phys. 41, 769 (1981).

78. R. C. Axtmann, "Environmental Impact of a Geothermal Power Plant," Science 187, 795 (1975).

79. K. D. Pimentel, R. R. Ireland, and G. A. Tompkins, "Chemical Fingerprints to Assess the Effects of Geothermal Development on Water Quality in Imperial Valley," Geotherm. Resour. Counc. Trans. 2, 527 (1978).

80. Pacific Gas and Electric Co. (PG\&E), Application for Certification. Geysers Unit 16, PG\&E, San Francisco, CA (1979), vol. I.

81. U.S. Environmental Protection Agency (EPA), Ambient Water Quality Criteria for Arsenic, U.S. EPA, Washington, DC, PB81-117327 (1980).

82. W. P. Tseng, "Effects and Dose-Response Relationships of Skin Cancer and Blackfoot Disease with Arsenic," Environ. Health Perspect. 19, 109 (1977). 
83. W. P. Tseng, H. M. Chu, S. W. How, I. M. Fong, C. S. Ling, and S. Yeh, "Prevalence of Skin Cancer in an Endemic Area of Chronic Arsenicism in Taiwan," J. Nat. Cancer Inst. 40, 453 (1968).

84. E. J. Underwood, Trace Elements in Human and Animal Nutrition (Academic Press, New York, 1977).

85. G. W. Coulter, "A Preliminary Appreciation of Effects on Aquatic Environments of Geothermal Power Development in New Zealand," Geotherm. Resour. Counc. Trans. $\underline{2}, 119$ (1978).

86. F. J. Nielson, S. H. Givand, and D. R. Myron, "Evidence of a Possible Requirement for Arsenic by the Rat," Fed. Proc. 34, 923 (1975).

87. M. Anke, M. Grun, and M. Partschefeld, "The Essentiality of Arsenic for Animals," in Trace Substances in Environmental Health-X, D. D. Hemphill, Ed. (University of Missouri, Columbia, MO, 1976), p. 403.

88. W. Mertz, "The Essential Trace Elements," Science 213, 1332 (1981).

89. J. H. Duffus, Environmental Toxicology (John Wiley and Sons, New York, 1980).

90. E. J. Calabrese, Pollutants and High-Risk Groups (John Wiley and Sons, New York, 1978).

91. J. L. Valentine, H. K. Kanz, and G. Spivey, "Arsenic Levels in Human Blood, Urine, and Hair in Response to Exposure via Drinking Water," Environ. Res. 20, 24 (1979).

92. J. L. Hahn, "Occupational Hazards Associated with Geothermal Energy," Geotherm. Resour. Counc. Trans. 3, 283 (1979).

93. J. L. Hahn, Evaluation of Occupational Hazards in the Geothermal Energy Industry, California Department of Health Services, Berkeley, CA (in preparation).

94. M. A. Zerwas, C. R. Witwer, R. E. Freeman, A. Salazar, and K. Semrau, Occupational Health Assessment of the Geothermal Hydrothermal Convection Industry, SRI International, Menlo Park, CA (1979). 
95. C. G. Schwarzer, "Recycling Hazardous Wastes," Environ. Sci. Technol. 13, 166 (1979).

96. G. Ahlborg, "Hydrogen Sulfide Poisoning in the Shale Oil Industry," AMA Arch. Ind. Hyg. Occup. Med. 3, 247 (1951).

97. G. A. Poda, "Hydrogen Sulfide Can Be Handled Safely," Arch. Environ. Health 12, 795 (1966).

98. R. J. Walinchus and M. S. Fox, Geothermal Energy Plant (Hydrothermal Flashed Steam). Environmental Characterization Information Report, U.S. Department of Energy, Washington, DC (in press).

99. B. L. Cohen, "Perspective on Occupational Mortality Risks," Health Phys. 40, 703 (1981).

100. E. Baginsky, Occupational Disease in California 1974, State of California, Department of Health, Berkeley, CA (1974).

101. B. L. Malloch, M. K. Eaton, and N. L. Crane, Assessment of Vegetation Stress and Damage Near The Geysers Power Plant Units, Department of Engineering Research, Pacific Gas and Electric Co., San Ramon, CA, 420-79-3 (1979).

102. C. R. Thompson and G. Kats, "Effects of Continuous $\mathrm{H}_{2} \mathrm{~S}$ Fumigation on Crop and Forest Plants," Environ. Sci. Technol. 12, 550 (1978).

103. C. R. Thompson, G. Kats, and R. W. Lennox, "Effects of Fumigating Crops with Hydrogen Sulfide or Sulfur Dioxide," Calif. Agric. 33 (3), 9 (1979).

104. J. R. Kercher, "An Assessment of the Impact on Crops of Effluent Gases from Geothermal Energy Development in the Imperial Valley, California," J. Environ. Manage. (in press). 
105. R. Sung, W. Murphy, J. Reitzel, L. Leventhal, W. Goodwin, and L. Friedman, Surface Containment for Geothermal Brines, TRW Inc., Redondo Beach, CA, T-5003 (1979). 